\title{
Gas Chromatography Vacuum Ultraviolet Spectroscopy: A Review
}

Aleksandra Lelevic ${ }^{\mathrm{a}, \mathrm{b},{ }^{*}}$, Vincent Souchon ${ }^{\mathrm{a}}$, Maxime Moreaud ${ }^{\mathrm{a}, \mathrm{c}}$, Chantal Lorentz ${ }^{\mathrm{b}}$, Christophe Geantet $^{\mathrm{b}}$

a. IFP Energies nouvelles, Rond-point de l'échangeur de Solaize BP 3, 69360 Solaize, France

b. Université de Lyon, IRCELYON, UMR5256 CNRS-UCB Lyon 1, 2 Avenue Albert Einstein, 69626 Villeurbanne Cedex, France.

c. MINESParisTech, PSL-ResearchUniversity, CMM, 35 rue Saint Honoré,77305

Fontainebleau, France

* Author for correspondence: aleksandra.lelevic@ifpen.fr

\author{
Abbreviations \\ VUV - Vacuum ultraviolet \\ GC $\times$ GC - Comprehensive gas chromatography \\ MDGC - Multidimensional gas chromatography \\ ${ }^{1} \mathrm{D}$ - First dimension \\ ${ }^{2} \mathrm{D}$ - Second dimension
}

Received: 31/07/2019; Revised: 13/11/2019; Accepted: 15/11/2019

This article has been accepted for publication and undergone full peer review but has not been through the copyediting, typesetting, pagination and proofreading process, which may lead to differences between this version and the Version of Record. Please cite this article as doi: 10.1002/jssc. 201900770.

This article is protected by copyright. All rights reserved. 
EI - Electronic ionization

FAME - Fatty acid methyl ester

DMN - Dimethylnaphthalenes

IL- Ionic liquid

DCB - Dichlorobenzene

TID - Time interval deconvolution

QMS - Quadrupole mass spectrometer

TOFMS - Time-of-flight mass spectrometer

FID - Flame ionization detector

HS - Headspace

Key words: Vacuum ultraviolet spectroscopy, gas chromatography, comprehensive gas chromatography, qualitative analysis , quantitative analysis 


\begin{abstract}
Accelerated technological progress and increased complexity of interrogated matrices imposes a demand for fast, powerful and resolutive analysis techniques. GC has been for a long time a 'go-to' technique for the analysis of mixtures of volatile and semi-volatile compounds. Coupling of the several dimensions of GC separation has allowed to access a realm of improved separations in the terms of increased separation power and detection sensitivity. Especially comprehensive separations offer an insight into detailed sample composition for complex samples. Combining these advanced separation techniques with an informative detection system such as Vacuum Ultraviolet spectroscopy is therefore of great interest. Almost all molecules absorb the Vacuum ultraviolet radiation and have distinct spectral features with compound classes exhibiting spectral signature similarities. Spectral information can be 'filtered' to extract the response in the most informative spectral ranges. Developed algorithms allow spectral mixture estimation of coeluting species. Vacuum ultraviolet detector follows Beer-Lambert law, with the possibility of calibrationless quantitation. The purpose of this article is to provide an overview of the features and specificities of GC-Vacuum Ultraviolet spectroscopy coupling which has gained interest since the recent introduction of a commercial Vacuum Ultraviolet detector. Potentials and limitations, relevant theoretical considerations, recent advances and applications are explored.
\end{abstract}




\section{Introduction}

Gas Chromatography (GC) is an established technique for the analysis of volatile and semivolatile compounds. Improvements of GC systems and developments of new stationary phases have enabled very good separation capabilities for a wide range of applications. Advances in terms of superposing several dimensions of separation and realizing $\mathrm{GC} \times \mathrm{GC}$ and even possibly $\mathrm{GC} \times \mathrm{GC} \times \mathrm{GC}[1]$ separations have enabled the analysis of extremely complex samples for whose separation capabilities of 1D GC are not sufficient. Typical example of matrices non-amenable to 1D GC, for their exhaustive characterization, are the heavier fractions of petroleum ( $>\mathrm{C} 10)$. To gain a perception into the composition of such complex samples, extremely resolutive analytical solutions are necessary. GC or GC $\times \mathrm{GC}$ in combination with FID detection allows quantitation of $\mathrm{C}$ containing species, however it offers no direct qualitative information. Coupling of the comprehensive separation with informative detection techniques such as MS can aid in qualitative characterization of complex media. MS however requires fastidious calibrations for quantification of targeted analytes, user's expertise and results in a large laboratory footprint. Problems with many of the detection techniques commonly used with GC are insufficient sensitivity and selectivity of the response, in the case of $\mathrm{GC} \times \mathrm{GC}$ also the lack of acquisition speed. One detection technique that would meet all the requirements and fit all application areas does not exist. Among all the detection techniques that may be encountered, spectroscopic techniques are very interesting. In particular, the broad band VUV absorption spectroscopy has gained attention in the last couple of years due to the recent availability of commercial instrumentation. Owing to the interesting features of this detection technique numerous applications but also standardized GC-VUV methods have been developed. A first review of 
this technology and summary of the first applications was provided by Santos and Schug [2]. The purpose of our work is to offer an update on the most recent advances in the application of $\mathrm{GC}(\mathrm{GC} \times \mathrm{GC})$-VUV technology and enlighten on the important features of $\mathrm{GC}(\mathrm{GC} \times \mathrm{GC})$ VUV coupling.

\section{Vacuum ultraviolet spectroscopy}

According to modern classification of solar irradiance spectral categories (ISO 21348), VUV spectral range encompasses wavelengths region from 10 to $200 \mathrm{~nm}$ [3], or photon energies from 6.2 to $124 \mathrm{eV}$. Nearly all chemical species absorb strongly and have unique absorption cross sections in the VUV wavelength range $[4,5]$. As it can be seen on Figure 1, absorption of water in the low-UV region is stronger by several orders of magnitude than its absorptivity in the IR region. Transitions in this region involve the excitation of nonbonding electrons to $\sigma^{*}$ orbitals whose molar absorptivities are low to intermediate and are usually in the range between 100 and $3000 \mathrm{~L} \cdot \mathrm{mol}^{-1} \cdot \mathrm{cm}^{-1}[4]$. At these wavelengths, there exist sufficient energy to photodissociate most organic molecules which leads to the presence of some ionized or photolyzed species in the measuring volume [6]. VUV light thus can be employed as an ionization source for MS [6]. Additionally, secondary chemical reactions such as chemical ionization by proton transfer may occur [7]. However, relative concentration of these ionized species is low and the detection of intact molecules is possible because of potential ion neutralization and low cross section for photodegradation processes within the VUV cell [8]. 
When it comes to the electronic transitions involved, low-UV radiation allows to explore Rydberg transitions of liquids, hydrogen bonds and hydration of water, aqueous solutions, and inorganic and organic molecules; it allows the analysis of gas, solid or liquid samples as spectral features are sensitive to chemical bonding, molecular conformations and molecular environment; sensitive quantitative analysis is possible as absorptivity of most species in this region is quite high but also dependent on compound's concentration and the conditions of temperature, pH, etc. $[9,10]$. Recently, Mao et al. [11] investigated VUV absorbance of alkanes by combining experimental VUV spectral data and the results of theoretical quantum mechanics calculations. They confirmed that the excitations involved in alkanes are of the Rydberg type and further elaborated on the influence of the molecular structure on the appearance of the absorbance edges for linear and cyclic alkanes.

Another interesting feature of VUV absorbance spectroscopy is the possibility of discrimination between isomers [12,13], small [14] and labile compounds [15] owing to their highly featured spectral signatures, while they traditionally pose a problem for MS detection. All compounds exhibit absorbance at low wavelengths hence selectivity in this range is lower. The specificity is the best towards unsaturated compounds exhibiting $\pi \rightarrow \pi^{*}$ transitions owing to their intense absorbance at wavelengths longer than $170 \mathrm{~nm}$. Figure 2 illustrates the VUV spectra for few selected hydrocarbons. Depending on the molecular structure, distinct and characteristic spectral features can be observed. Saturated, monoaromatic and diaromatic species in question can hence be easily differentiated. Polyaromatics species dominantly absorb at wavelengths longer than $240 \mathrm{~nm}$. It is often difficult to differentiate between conjugated and non-conjugated diolefins by conventional methods, however VUV absorbance spectra of conjugated diolefins show significant 
absorbance at 200-240 nm, while nonconjugated diolefins exhibit hardly any response in this wavelength region. Isomers, which can be challenging for MS can be easily distinguished by VUV. This was demonstrated on the examples of naphthols and xylenes [5], cis- and transfatty acids [16] and their methyl esters [13], dimethylnaphthalenes [17], dichlorobenzenes [8], carbohydrate isomers [18], methyl benzophenons [19], nitroaromatics [20], isomeric pesticides [15], terpenes [21], fentanyl analogues [22]. Aromatic compounds spectra are very elaborate with additional functional groups adding new spectral features. In general it was observed that the increase in the number of aromatic rings [23] or double bonds [16] causes a shift of the absorbance maxima towards longer wavelengths. The steeper slope in the aliphatic region of the aromatic species spectra can signify the increasing length of the alkyl chains, while the increase of the number of alkyl chains connected to the aromatic ring causes a bathochromic shift of the absorbance maxima [23].

In addition to qualitative characterization, quantitative information can be extracted owing to VUV absorbance following the Beer-Lambert Law. If molecular cross sections are known, even calibrationless quantification is a possibility [24]. Additionally, as Beer-Lambert law is linear and additive, linear spectral mixture estimation algorithms can be used to investigate the composition of mixtures [25]. This often requires the predetermination of spectra (i.e molecular cross sections) for the reference compounds.

Computation of the theoretical VUV/UV spectra is possible using a variety of methods ranging from semiempirical approaches and the density functional theory calculations to more sophisticated methods $[5,17,26]$. Schenk and colleagues [17] performed a comparison of the time dependent density functional theory computed spectra and the experimental This article is protected by copyright. All rights reserved. 
spectra of the assorted dimethylnaphthalene isomers. They observed that the most important features of the experimental spectra were nicely reproduced in the theoretical one. The theoretical spectra demonstrated the correct order of the main peak positions, as well as relative peak intensities. Skultety and coworkers [12] also employed time-dependent density functional theory to model theoretical VUV spectra for an isomeric set of new designer stimulant drugs, for which library spectra were not available. Assignment was performed with least square optimization by identifying the theoretical spectrum for which the sum of the squared residuals, when compared to the experimental spectrum, was the lowest. Many of the structures were correctly identified based on such computational approach. When correct assignment was not achieved, authors assumed that this was owing to the disadvantage of the approach that the computed spectra were based on a single fixed structure, while in reality, molecules are flexible. Hence, it is necessary to take into the account all practical conformations of the molecule. Ponduru et al. [27] compared GC-VUV data with time-DFT for the computation of the absorption spectra for oxidation monitoring of polycyclic aromatic hydrocarbons (anthracene, naphthalene, and pyrene). The use of experimental absorption spectra, combined with spectral library matching, and computed absorption spectra provided good results (Figure 3), however they concluded that improvements in computational methods are needed in order to derive more experimental-like spectra. In the recent work, Mao et al. [28] investigated the possibility of PIONA class compounds VUV spectra simulation by employing time-dependent density functional theory. Good correlation between theoretical calculation and experimental spectra was obtained. TDDFT methods optimized parameters proved to be quite stable over a wide range of PIONA compounds, allowing for possibility of heavier PIONA compounds spectra simulation with good confidence. As in the previous work, it was concluded that further improvements in computational methods are necessary. 
VUV absorption spectroscopy being a universal detection technique allows to probe the electronic transitions exhibited virtually by all compounds (with the exception of noble gases, hydrogen and nitrogen which exhibit minimum absorption characteristics). This feature is particularly interesting as these gases are the commonly used carrier gases for gas chromatography.

\section{Vacuum ultraviolet spectroscopy coupling with GC}

\subsection{Spectroscopy as a detection technique for GC}

1D GC is a 'go-to' technique for the analysis of volatile and semi-volatile samples.

Regulatory and industrial methods still rely heavily on the elaboration of this technique coupled with different detection solutions, including FID or MS [2]. Despite having unsurpassed qualitative analytical capabilities, MS involves complex instrumentation and elaborate quantification. MS also often falls short in certain areas where isomeric and isobaric analytes ought to be differentiated [29] and in all cases where similar fragmentation patterns are incurred, especially if analytes are additionally coeluting. The resolution of coeluted compounds requires sophisticated algorithms and softwares to tease apart temporal changes in complex fragmentation spectra [30]. Comparison of the basic features of the detection techniques commonly applied in combination with GC, including VUV, is summarized in $[2]$. 
Among the numerous detection techniques that are amenable to coupling with GC, spectroscopic measurements are known to be very reliable in terms of precision and accuracy. When employed in the gas phase, spectroscopy can provide superior information compared to conventional liquid medium profiling. In liquids, solvent effect is dominant, hence it tends to obscure the vibrational features of the compounds. However, the most significant drawback is that the solvent wavelength "cut-off" restricts the highly informative wavelength range below $\sim 195 \mathrm{~nm}[31]$. In the gas phase, many of the incurred solvent effects are absent. Gas-phase spectra have been found to be characteristic for the absorbing species and to exhibit very elaborate features in most cases. Furthermore, families of compounds tend to exhibit spectral similarities.

IR spectroscopic detectors assay the interactions of the mid-IR light with the sample. IR detectors are highly informative regarding the structure of the interrogated molecules. However, molecules tend to possess small absorption cross-sections in the IR range, hence leading to inferior sensitivity of the detection [32].

Atomic Emission Detector, while being destructive and giving only elemental information, is another significant example of spectroscopic detectors employed for gas chromatography [33]. This detector offers multielement detection with an equimolar response (compoundindependent) [34,35]. However, for this detector spectral interferences must be identified and eliminated. For example, it has been demonstrated that compounds containing CO functional group are likely to emit in the same spectral region as sulphur [36]. Additionally, its sensitivity is element specific, e.g. its response for oxygen is low compared with that for carbon or hydrogen [37].

This article is protected by copyright. All rights reserved. 
UV spectroscopy has been used with GC during the past 40 years [38]. Advantages of the conventional UV spectrometers include: reliable qualitative and quantitative information, possibility of very simple instrumentation [39], detection of organic and inorganic compounds. When moving towards low-UV range sensitivity becomes orders of magnitudes higher however the loss in fingerprint selectivity is incurred [40]. The advantages of a UV detector for GC have long been recognized [38,41,42], but the instrument development was lagging. This is especially true for the low end-UV range, since owing to high absorption of most compounds instruments ought to be purged by nitrogen or employed in the vacuum environment and designed with specific transparent optical windows. Despite the slow developments, research into the possibility of employing VUV as a detection method for GC continued and did not fail to demonstrate the numerous advantages of the technique. Recent appearance of the commercial VUV system gave a new insight into the analytical capabilities of the detection in the VUV range.

\subsection{Vacuum ultraviolet spectroscopy as a detection method for GC}

First applications of the vacuum ultraviolet spectroscopy $(10-200 \mathrm{~nm})$ were mostly limited to synchrotron light source application $[43,44]$ (in order to compensate for significant background absorption [5]) and single wavelength photodiodes [45-47]. Lagesson and coworkers [31] introduced in 1998 a novel system offering broad band absorption monitoring in the VUV/UV region (168-330 nm). They performed studies of the absorption spectra for $\sim 1000$ organic compounds and a number of inorganic gases. Very important finding was that for all the spectra recorded, 69\% showed absorption maxima at wavelengths shorter than 190 $\mathrm{nm}$ and circa $87 \%$ at wavelengths shorter than $200 \mathrm{~nm}$.

This article is protected by copyright. All rights reserved. 
After 2000, studies involving GC-VUV have been sparse, essentially due to the lack of commercial instrumentation. This recently changed with the introduction of a benchtop spectrometer delivering full absorption spectra in the VUV wavelength region (down to 125 nm) within milliseconds (VUV Analytics ${ }^{\circledR}$ ) [5]. Since the launch of this universal nondestructive detection technique offering qualitative and quantitative measurements, a progressive surge in studies involving diverse applications has been witnessed. Figure 4 illustrates the timelines of the VUV detection technique evolution and the main developments in terms of GC-VUV configuration.

\subsubsection{Technical considerations}

Technical overview and the working principle of the new VUV-spectrometer is described elsewhere [5]. Briefly, GC effluent is directed via a stainless steel transfer line into a $10 \mathrm{~cm}$ long flow cell. After passing through the VUV flow cell, a broad band light, emitted from a deuterium lamp, is directed onto a holographic grating. Transmitted wavelengths from 125 to $240 \mathrm{~nm}$ (430 nm for the second generation instrument) are then focused onto a back-thinned CCD detector. In the flow cell, make-up gas (nitrogen, argon, or other) is introduced, while the flow cell itself and the transfer line are kept at elevated temperature. Acquisition frequency depending on the instrument can be up to ca. $90 \mathrm{~Hz}$. Lower frequencies are preferred as elevated acquisition rates induce significant noise. However, in this case care must be taken that sufficient number of data points are sampled across each chromatographic peak. 
In the GC-VUV coupling main technical considerations are related to make-up gas pressure regulation. Make-up gas flow is more critical in the earlier version of the VUV detector (VGA-100) where, owing to the larger size of the flow cell $(80 \mu 1)$, more significant peak dispersion can be incurred. This phenomenon is related to the diffusion coefficient of the analyte and is more prominent for lower molecular weight species [48]. In such cases, decreasing the residence time in the volume of the detector flow cell can aid in reducing the peak broadening. This however further reduces the time that eluent spends in the cell adversely affecting the signal averaging time and hence the intensity of the signal decreases. Concerns regarding the peak widths owing to the size of the VUV flow cell have significantly decreased with the introduction of the new VUV detector version (VGA-101) featuring reduced size of the flow cell $\sim 40 \mu 1$.

Most authors have reported a 'mass-dependent' response of the VUV detector [5,24,48]. In the case of mass sensitive detectors peak height is proportional to the mass flow, while peak area being an integration of the detector response over time is dependent only on the absolute mass of the analyte in the carrier gas [49]. However, the perceived global detector response behavior as a function of analyte concentration or absolute quantity in the given time strongly depends on the particular set-up and involved flow regulation. For the systems featuring additional make-up gas supply detector response behavior can be less straightforward. VUV detector follows Beer-Lambert law, hence it is a concentration sensitive detector $[50,51]$. However, in certain cases VUV detector can appear to exhibit mass dependent response. This is owing to the additional make-up gas supply and combined influence of the GC effluent and make-up gas on the analyte concentration in the VUV flow cell [51]. 
Temperatures of the VUV transfer line and the flow cell ought to be maintained high enough in order to avoid condensation of the high boiling constituents, their loss and fouling of the instrument. The optimal approach is keeping these temperatures dozen of degrees higher than the final temperature of the GC separation. As GC-VUV set-up has two thermal zones, on one side GC oven and on the other VUV transfer line and flow cell, during a temperature programmed GC run, effluent flow in the VUV flow cell will slightly increase. This is due to the elevated temperature of the VUV which generates an additional pressure resistance. Flow variations might affect the quantitation performance especially at higher GC flows, hence the possible effects on quantification ought to be investigated.

\subsubsection{Qualitative analysis}

As mentioned in the previous Section, VUV spectrometer allows absorbance monitoring at wavelengths down to $125 \mathrm{~nm}$. During each detector scan a full range absorbance spectrum is obtained and a chromatogram can be generated by using any number of wavelength ranges. Typical acquisition time of one spectra is ca. $11 \mathrm{~ms}$. Generally, the response in the 125-240 $\mathrm{nm}$ range is employed to visualize the entire chromatogram since the use of the longer wavelengths induces significant noise. Average detector response over an investigated range denoted as 'spectral filters' can be employed to selectively highlight the presence of compounds which preferentially absorb in the given region [52]. Aromatic compounds can be highlighted by averaging the response in the wavelength range where their absorbance is maximal i.e. 170-200 $\mathrm{nm}$. Spectral filter employing the wavelength range 125-160 $\mathrm{nm}$ can 
highlight the presence of saturated compounds, while at 200-240 nm diaromatics or conjugated di-olefins can be accentuated. Since all compounds absorb at lower wavelengths, selectivity significantly increases with moving towards longer wavelengths.

VUV absorbance detection allows to distinguish many compounds, however it possesses limited differentiation ability for species possessing similar spectral signatures. In such cases chromatographic resolution is necessary to achieve discrimination of investigated species. Santos et al. [53] employed GC-VUV for qualitative and quantitative determination of fatty acids in blood plasma. FAMEWAX column was selected to obtain additional resolution for the positional isomers (C16:1 (n-7 and n-9) and C18:1 (n-7 and n-9)) for which VUV spectra exhibited high similarity. Lack of selectivity can also be overcome by coupling VUV spectrometer with a complementary detection technique such as MS. VUV-MS coupling in series has been recently proposed in the works by Anthony et al. $[8,54]$. They demonstrated that tandem GC/VUV-MS chemical identification approach that employs databases from GC, VUV spectroscopy and MS results in a much improved identification of chemical mixtures examined, owing to a better identification of analytes challenging to distinguish by VUV (e.g., alkanes) or MS alone (e.g., isomers). VUV exhaust transfer line was rerouted to exit through the VUV via a stainless steel heated transfer line and into a triple quadrupole mass spectrometer (TQMS). This instrumental set-up allowed to maintain MS ionization source pressure of 100 to 150 mTorr within a GC run while the VUV flow-cell registered -0.105 psig. No significant peak broadening was obtained when VUV was introduced, however slight shift of retention times for aromatic compounds was observed. Additionally, no marked difference in abundance of ions in the mass spectra after the introduction of VUV was observed. Main concerns were related to maintaining a low pressure on the side of the MS 
which inhibits the use of the make-up gas in the VUV flow cell. Not using the make-up can cause additional concerns due to quantification issues related to possible analyte losses. Dual VUV-MS detection in the split mode was also demonstrated [22], however detailed investigation of the possible influence of VUV on the MS quantitation was not made.

\subsubsection{Quantitative analysis}

Depending on their molecular cross section, compounds exhibit different VUV response. VUV detector follows Beer-Lambert law with a 2-3 orders of magnitude dynamic range. VUV spectra over time for a mixture of compounds can be represented as a matrix, which is a product of a concentration profile matrix and a matrix of spectral features for each of the compounds (see Figure 5). This implies that from the observed spectra ('A'), concentration profiles can be calculated and the concentration of each compound in the mixture inferred leading to quantitative results. This can be achieved by employing relative response factors for a specific range of wavelengths but also with a matrix approach exploiting all of the observed wavelengths. Both 'supervised' [25] quantitative methods where response factors are already known (based on reference spectra) and 'unsupervised' [20] approaches where they are computed for unknown coeluted compounds were explored.

Estimation of the relative response factors (RRFs) which allow to convert VUV response area to mass percent was demonstrated in several works $[23,25,52]$. RRFs can be calculated as an average for a family of compounds in order to achieve a group type quantification. It was found that n-alkanes (starting from C4) exhibit similar VUV RRFs especially when a wide 
wavelength range is considered in accordance with their similar spectral features [25], while for aromatics more variability in RRFs is present. For the PIONA class molecules, it was observed that the absorbance for a given mass of compound tends to be relatively uniform [25]. Weber et al. [52] performed mass percent quantification of saturates, mono, di, and polyaromatics in diesel type samples. Quantification was achieved by dividing 125-240 nm filtered chromatogram into three regions corresponding to contributions from each of the families, the start of the naphthalene peak and the start of the anthracene peak being taken as the points of division between the three investigated classes. RRFs for saturates and monoaromatics were obtained from prior studies [25] while diaromatic and polyaromatic responses were calculated based on the dynamic filtering approach and standard addition data. More significant errors were obtained in the quantification of polyaromatics owing to their lower abundance $(<1 \%)$. García-Cicourel and Janssen [23] developed a GC-VUV method for the measurement of the total level of aromatic hydrocarbons in purified mineral oils. Relative response factors for alkanes were taken to be $\sim 0.77$ relative to methane in accordance with previous works $[25,52]$. Aromatic species response factor was calculated as an average for the eight investigated mineral oils aromatic fractions, relative to the response of saturates. The minimum MOAH level determined with this method was approximately $0.13 \%$ and RSD values achieved were better than $8 \%$.

Theoretically, VUV detection allows for pseudo-absolute quantification of analytes based on the pre-recorded cross sections without the need for conventional calibration [24]. Namely, the analyte peak area depends on several factors: the amount of analyte, the total flow rate (GC flow rate plus make-up gas flow rate), flow cell dimensions and the absorption crosssection of the analyte over a specified wavelength range. When the analyte's cross-section is 
known, the amount of analyte can be deduced from the measured peak area, thus limiting the need for calibration. Cross-sections being measured quantities have various systematic errors associated with their estimated values [24], however they can be refined over time based on repeated analysis and the use of improved instrumental techniques [55]. Bai et al. [24] evaluated in their study the use of the pseudo-absolute method in order to experimentally determine the sources of sample loss and gain associated with sample introduction into a typical gas chromatograph. Unknown concentration of one analyte can also be determined based on the relative peak areas if cross sections of the analyte and the chosen internal standard are known. Such approach removes any dependence on instrumental parameters and accounts for systematic errors, as long as consistent settings are used to measure the peak areas. Internal Standard-Based Pseudo-Absolute Quantitation was demonstrated in the work by Zoccali et al. [55]. Error estimation was made for detected amounts based on comparison with the original analyte concentrations. Owing to the influence of many factors that can contribute to systematic error accumulation, authors concluded that additional work is necessary for full delineation of error propagation.

To exploit the full potential of the GC-VUV for quantification purposes of coeluting compounds, some work has been undertaken to develop spectral mixture estimation algorithms based on the spectral libraries.

The first published example of such an algorithm for GC-VUV data is the "time interval deconvolution' (TID) algorithm. This 'supervised' approach is based on estimating a linear combination of known spectra in the given time slices where known compounds coelute. For TID application reference library spectra, assigned retention indexes and relative response 
factors for each compound/class of interest are necessary. Use of the automated approach to TID was first demonstrated by Walsh et al. [25] for the purpose of bulk characterization of gasoline samples (PIONA type analysis). For now the only commercial software that offers automated decomposition is offered by VUV Analytics. Several research works have demonstrated the power of the technique for spectral mixture estimation of coeluted species even if there is no temporal resolution between them [13-15,21,53,56-58]. This methodology was successfully applied in the ASTM D8071 standard test method for the quantification of hydrocarbon classes in gasoline-range fuels (PIONA analysis) [59]. Similar standardization work is under progress for kerosene fuels [60].

In the study by Schenk et al. [17] it was found that, under reasonable injection conditions, all of the pairwise overlapping dimethylnaphthalenes isomers tested could be estimated up to nearly two orders of magnitude in relative abundance (up to 99:1). For TID application, important indicator was demonstrated to be the pair-wise sum of squared residuals (SSR) between normalized reference spectra. For example, in [18] coeluting carbohydrate isomers demonstrated low SSR values (0.25 and lower). In these cases, the relative abundance of overlapping compounds that can be estimated is lower (50:1 relative abundance). Weston et al. [61] in their study performed a comparison of the spectral profile of isotopically-labeled compounds with their non-labeled equivalent. In the case of tested benzene isotopologues, absorption spectra demonstrated small differences. However, increasing degree of deuteration generally increased the difference between labeled and non-labeled counterparts. It was concluded that sufficient spectra dissimilarity (e.g. SSR $>1$ or higher) is needed for mixture estimation of investigated species in a practical abundance range $(>10: 1)$. Work by Schenk et al. [18] demonstrated that the accuracy of the analysis however can be significantly 
compromised where coeluted peaks needed to be estimated compared to determinations from fully resolved peaks. In this study, estimated on-column amounts of investigated carbohydrates were compared with the amounts obtained after peak deconvolution. RSDs obtained were higher than $50 \%$ in certain cases. In the work by Qiu et al. [56] an automated time interval deconvolution (TID) procedure was applied to rapidly speciate individual PCBs, as well as classify commercial Aroclor mixtures based on their degree of chlorination. Very good results for with good specificity and sensitivity were obtained.

Spectral mixture estimation approaches are additionally limited by the lack of the reference spectra which inhibits their application to more complex samples. Existing VUV spectral library contains approx. 2000 reference spectra of mostly organic compounds. Compounds can be segregated by class such as for example PIONA molecules. Spectra are mostly acquired by analyzing standard compounds. Reference VUV spectra can also be extracted by analyzing real samples and by performing spectral mixture decomposition [62].

As an alternative to TID, Reiss et al. [20] recently presented an 'unsupervised' approach allowing to perform spectral decomposition termed non-negative matrix factorization. This approach in contrast to TID allows mixture estimation for compounds which are unknown without pre-determined retention indices and a spectral library, hence it is suitable for discovery-based analysis. The two approaches were compared and both exhibited good alignment for the investigated compounds and good comparability with each other (Figure 6). However, NMF drawbacks compared to the TID include inability to decompose the signal in the case of similar signals (similar as TID) and the lack of separable maxima (only up to an overlap of $33 \%$ ), additionally number of compounds in a coeluting peak must be known. 
Pairwise mixtures of compounds present in the amounts down to 10:1 could have been successfully estimated, compared with the 99:1 for TID as determined previously.

In terms of quantification performance, most cited disadvantages of the VUV detection are limited dynamic linear range and limited sensitivity. LODs in the low ppm range or low ng on column were reported for most compounds (see references from Table 1). Large-volume injection was used to enable better detection limits in [53]. LODs can be artificially improved by selecting appropriate spectral filters but also by applying lower acquisition frequencies. In the latter case improved signal averaging results in a smoother baseline [58]. Mentioned disadvantages can be also compensated by coupling VUV with a powerful quantitative detector such as FID. Weatherly and co-workers [16] demonstrated that the additional nonhyphenated FID analysis provides supplementary resolution to successfully discern classes of cis and trans isomers of FA esters. VUV-FID direct hyphenation is completely feasible; although rather in the parallel detection mode with a split rather than in series. The latter requires installing a heated transfer line that would enable to transfer peaks from the VUV cell towards the next detector in a way to avoid significant band broadening. In the case of parallel dual VUV-FID detection, owing to pressure resistance introduced by the VUV heated zones which causes the evolution of the GC flow during the run, possibility of analyte discrimination (especially at higher flows) and influence on the FID quantification ought to be investigated.

In several studies precision and accuracy of the employed GC-VUV method was investigated and compared with conventional GC-FID and GC-MS methods. 
Dunkle et al. [50] compared GC-VUV with GC $\times$ GC-FID and DHA for PIONA compounds quantification. For all methods comparable RSD values were obtained. Tests involving five injections a day during three days yielded RSDs better than 1.3\%. PIONA results obtained with GC-VUV were within $0.6 \%$ of the actual levels in the sample The largest deviations in quantification were obtained with the DHA method, resulting from incurred misidentification of olefins. Bai et al. [63] performed a comparison of GC $\times$ GC-TOFMS, GC-FID and GCVUV for the determination of diesel biomarker ratios in diesel fuels. Good agreement between GC-FID and GC-VUV results was demonstrated. Measurements were performed in triplicate yielding Pristane/C17 and Phytane/C18 ratios variability on the range of $10 \%$ for both techniques. Precision better than 10\% was obtained also by Qiu et al. [21] in the analysis of terpene compounds. Pechancova et al. [19] compared GC-VUV with the conventional GC-MS for the analysis of photoinitiators in food packages. Results demonstrated that the relative difference between measured concentrations was not higher than $18 \%$. Spiking experiments in the study by Schenk et al. [64] have demonstrated good recovery for formic acid in phenol-formaldehyde.

\subsubsection{GC - Vacuum ultraviolet spectroscopy applications}

This Section gives a brief summary of the up-to-date applications involving GC-VUV. The focus is placed on reporting on the added benefits obtained by employing the VUV technique. Overview of the main findings in terms of both VUV advantages and disadvantages - is given in Table 1, along with details on the employed GC and VUV methods. 
It can be perceived that a wide variety of samples can be analyzed, with dominant interest and more than one third of overall applications in the Oil and Gas sector. For the analysis of real samples the main disadvantages of the VUV include its limited sensitivity, but also its universal detection characteristics resulting in limited specificity in such complex matrices.

\subsubsection{Oil and Gas}

Features of the new VUV absorbance detector have proven to be particularly interesting for liquid and gaseous fuels analysis. Possibility of the qualitative and quantitative characterization of the wide variety of hydrocarbons, but also spectral mixture estimation capabilities have enabled both group type and detailed analysis of fuel streams. First elaboration of the potentials of the novel detection technique was provided in the research paper by Schug et al. [5] where VUV capabilities for hydrocarbons characterization have been demonstrated. Permanent gases analysis [14] has demonstrated that even small molecules such as C1-C5 linear and branched hydrocarbons, water, oxygen, nitrogen, methane, etc., all exhibit elaborate spectral features. Mixture estimation and spectral filtering additionally aid in discerning the response of individual compounds. The use of the automated approach based on TID to perform PIONA analysis of gasoline samples was first demonstrated by Walsh et al. [25]. The ability to perform fast and simple group type analysis of gasoline range hydrocarbons has led to the proposal of the D8071 ASTM method [59]. The purpose of this method is to allow easy and fast analysis of the bulk concentrations of hydrocarbon classes in gasoline (PIONA analysis). Application of this approach is however limited to the gasoline range fuels. For heavier petroleum cuts, TID capabilities are not sufficient owing to numerous coelution events but also limits of the existing VUV library. 
Group-type separation for diesel samples including light gas oils by using GC-VUV was demonstrated in the work by Weber et al. [52]. Highly polar ionic liquid stationary phases were employed to achieve separation of the diesel constituents into saturates, mono, di, and polyaromatics. Mass quantification of the three investigated families was performed.

Schenk et al. [17] interrogated capabilities of the GC-VUV for the analysis and mixtures estimation of dimethylnaphthalenes (DMN) isomers in jet and diesel fuel samples. DMN isomers are known to be challenging for the MS detection owing to significant coelution and their similar mass spectra. They can also have similar polarities and boiling points, hence finding a method able to provide differentiation between them, resolve mixture and facilitate assignment is very challenging. In the study, it was found that, under reasonable injection conditions, all of the pairwise overlapping isomers tested could be estimated up to nearly two orders of magnitude in relative abundance (up to 99:1).

Bai and co-workers [63] performed a comparison of GC-VUV, GC-FID and GC $\times$ GC-MS analysis for diesel fuel and weathered diesel fuel characterization. Common biomarkers fingerprinting was performed for fuel age and source identification. GC-FID was sufficient to define biomarker ratios, however not appropriate for more complex compositions owing to incurred coelutions. GC-VUV allowed to classify numerous peaks into different families with the aid of spectral filters and spectral mixture estimation. It was observed that weathering process leads to the reduction in the amount of lighter hydrocarbons and greater abundance of heavy compounds, as it can be seen on Figure 7. 
Liu and colleagues [58] recently evaluated the possibility of hyphenating short monolithic silica capillary columns with VUV detection for online monitoring of mixtures of light hydrocarbons. The set-up was modified by directly connecting the column to the VUV flow cell (at room temperature). Mixture of methane, ethane, carbon monoxide and carbon dioxide was chromatographically separated in $15 \mathrm{~s}$.

Dunkle and coworkers [50] performed a study in which they compared GC-VUV with the technique of DHA (detailed hydrocarbon analysis) and $\mathrm{GC} \times \mathrm{GC}-\mathrm{FID}$ for the analysis of liquid hydrocarbon streams. PIONA results comparison between the three techniques demonstrated good agreement with good repeatability. Compared to DHA, GC-VUV demonstrated reduced run time and less misidentification events (Figure 8). TID algorithm demonstrated good spectral mixtures estimation capabilities with good accuracy.

\subsubsection{Foods/Flavors/Fragrance/Oils}

Another significant field of interest for GC-VUV application is food and aroma compounds analysis.

Qiu and coworkers [21] employed GC-VUV for the investigation of 41 different standard terpenes. They all exhibited highly featured and easily differentiated spectra and demonstrated good quantification limits. 
Weatherly and co-workers [16] further studied the application of the VUV detection in combination with GC separation for the analysis of fatty acid methyl esters (FAMEs). They employed ionic liquid (IL) stationary phases in order to achieve improved resolution of longchain methyl and ethyl esters of omega-3, omega-6, and additional positional isomeric and stereoisomeric blends of fatty acids. In addition to improved separation capability of the chosen GC configuration, VUV analysis provided supplementary separation dimension allowing to achieve characterization of the investigated species.

Fan et al. [13] similarly investigated capabilities of the VUV detection for FAMEs analysis. VUV absorption spectra of 37 FAMEs, including saturated, monounsaturated, and polyunsaturated types were recorded. Unsaturated FAMEs exhibited significantly different gas phase absorption profiles compared to saturated ones, hence these classes could have been easily distinguished. Isomer species, such as cis/trans FAMEs were also easily differentiated. Multiple bond configurations of cis and trans isomers present together in the same molecule have not been studied however.

Anthony and coworkers $[8,54]$ demonstrated the advantages and technical considerations for VUV-MS coupling in series, with a goal of achieving improved characterization of structurally similar VOCs in perfume and essential oil samples. They demonstrated that multidomain VUV-MS library search of data as opposed to single-domain library search methods resulted in improved identification accuracy and confidence. Special metrics were developed in order to assess the reliability of library assignments. 
Pechancová et al. [19] performed a comparison of GC-MS and GC-VUV for the detection of photoinitiators in food packages. Their findings witnessed the advantages of the VUV detection for the discrimination of isomeric structures, such as methyl benzophenons which are non-discernable by MS detection, however in comparison with the GC-MS procedure, GC-VUV yielded worse detection limits.

García-Cicourel and Janssen [23] developed a fast GC-VUV method for the measurement of the total level of aromatic hydrocarbons in purified mineral oils without prior separation of aromatics and aliphatics. Mineral oil samples were investigated by GC-VUV but also saturates and aromatic prefractionation was performed and analysis carried out with GC-FID. Results obtained were compared and overall good agreement was obtained.

\subsubsection{Life sciences}

Schenk et al. [18] demonstrated the abilities of the VUV technique for qualitative and quantitative determination of mono-, di, and tri-saccharides. GC-MS characterization of these compounds is inhibited owing to their high structural complexity, chromatographic coelution and ambiguous fragmentation patterns. VUV enabled efficient differentiation of isomeric species such as ketopentoses and reducing versus non-reducing sugars.

In the doctoral dissertation by Muthal [65], GC-VUV was employed to detect glucocorticoids, steroidal hormones, commonly applied as adulterants in herbal medicinal 
products. Glucocorticoids were detected with a good detection limit. The study also showed the separation and detection of residual water in a solvent mixture after the solid phase microextraction.

Santos et al. [53] employed GC-VUV for qualitative and quantitative determination of fatty acids in blood plasma. TID was employed in order to aid in discerning responses of few coeluting species. Large-volume injection enabled better detection limits. FAMEWAX column was selected to obtain additional resolution for the positional isomers (C16:1 (n-7 and n-9) and C18:1 (n-7 and n-9)) for which VUV spectra exhibited high similarity.

Leghissa and colleagues [57] investigated applicability of the VUV for the detection of cannabinoids and their metabolites. They found that the capabilities of spectral mixture estimation aids to reduce requirements for chromatographic resolution, hence allow to employ simpler separation procedure, faster temperature ramps, etc. without sacrificing sensitivity. As in the previously mentioned work, LODs in the low ppm range were found. Coeluting analytes were successfully discerned trough automated spectral mixture estimation (TID).

Zheng and colleagues [66] employed VUV detection coupled with GC separation for the screening of trace level water content and impurity profiling and stability investigation of water sensitive 4-Ethoxy-1,1,1-trifluoro-3-buten-2-one (ETFBO) a starting material to develop a medicine to treat human immunodeficiency virus (HIV). Reliability and ability of 
the VUV detector to interrogate peak purity based on VUV spectral library matching was demonstrated.

Buchalter et al. [22] presented a study on the possibility of qualitative and quantitative analysis of fentanyl analogues by the means of GC in combination with cold EI MS and VUV, connected in parallel by employing a flow splitter. As in the previous studies, discerning isomeric species by VUV was emphasized, but also good quantitative results were obtained. LODs were in the range of high $\mathrm{ng} / \mathrm{ml}$ for both detectors, however between two to three times lower with VUV than the ones obtained by cold EI MS. Good sensitivity was facilitated by employing a spectral filter encompassing a 175-205 $\mathrm{nm}$ range of wavelengths, in which species containing aromatic functional groups demonstrate preferential absorption.

\subsubsection{Forensic}

Cruse and Goodpaster [67] evaluated GC-VUV for nitrate ester explosives analysis. Thermal degradation of the interrogated species in the VUV cell was investigated. Mixtures of gas phase products were detected and their relative amounts estimated by employing spectral subtraction. Intact and burned real samples were also analyzed testifying the potential of the technique. Conclusion was made however that LODs need to be improved. 
Skultety et al. [12] applied GC-VUV for forty-three designer drugs analysis. Many of isomers were easily differentiable by their VUV spectral features, spectral mixture estimation aided to resolve incurred coelutions.

Reiss et al. [20] evaluated the ability of VUV spectroscopy for the analysis of drug and explosive precursors as well as chemical warfare agent simulants. LODs obtained were in the low ng range for all compounds. Good nitroaromatic isomers differentiation was observed. Potential for forensic target compounds was evaluated using an artificially spiked gasoline matrix.

Roberson and Goodpaster [68] recently employed GC-VUV for the analysis of phenethylamines. Principal Component Analysis and Discriminant Analysis were employed. Distinct groups with small variations between replicates were obtained despite similar spectral features of the compounds. Differentiation of the stereosisomers ephedrine and pseudoephedrine proved to be feasible through the application of chemometrics.

\subsubsection{Environmental}

In the study by Fan et al. [15] various pesticides species proved to be amenable to VUV analysis. Within each class, different species displayed distinctive absorption spectra. The use of spectral filters allowed to discern pesticides containing aromatic structure from those that 
were not aromatic. Isomers exhibited distinctive spectra and could have been easily differentiated by VUV analysis.

Qiu et al. [56] demonstrated the analysis of 209 polychlorinated biphenyl congeners. All of the PCBs exhibited distinctive VUV spectra. Good detection limits were achieved.

Santos et al. [69] employed GC-VUV for the analysis of fatty acids methyl esters for bacterial identification and discrimination based on their fatty acid profile. 12 different bacteria genera and 15 species were successfully discerned. Principal component analysis (PCA) and cluster analysis were conducted to visualize the data and examine the homogeneity of bacterial species. Overall, saturated, branched, hydroxyl, cyclopropane and unsaturated fatty acids were identified. Distinct fatty acid profiles were obtained for each investigated microorganism.

In another work, Santos and coworkers [70] performed analysis of fatty acid and protein profiles for the bacteria grown in the presence of contaminants characteristic for certain oil and gas production processes, such as high salt levels, benzene, or alcohol. Obtained results were deemed to be potentially useful as indicators of the ecological health. Successful identification of bacterial FAMEs was achieved based on their absorbance spectra.

Schenk and co-workers [64] recently investigated the advantages of various approaches for identification and quantitation of formaldehyde leachates from proppants. HS-GC-MS, LCUV and HS-GC-VUV were compared. HS-GC-VUV was chosen in order to detect 
formaldehyde in its native form without derivatization, task nearly impossible with conventional EI-MS owing to its degradation. However, coelution of formaldehyde with water which was present in great abundance proved to be an obstacle for its detection even with the VUV mixture estimation capabilities. HS-GC-MS was found to be best suited for the investigated application.

\subsubsection{Other}

Diverse applications across multiple disciplines have also been a subject of interest including the characterization of isotopologues [61] or the oxidation monitoring of polycyclic aromatic hydrocarbons [27].

Shear-Laude [71] reported the quantitation of water by employing GC-VUV as a possible alternative to widely employed Karl Fischer titration. In this study, a GC-VUV method employing IL stationary phase was used to screen common solvents for their water content. GC-VUV exhibited a dynamic linear range for water between $10 \mathrm{ppm}$ and 10,000 ppm. For the measurement of water in methanol accuracy and precision were both better than $3.0 \%$. Replicate measurements of residual water content showed good precision and low limits of detection.

In general the main disadvantage cited for the VUV is the lack of sensitivity but also selectivity for homologues. Research works performed also demonstrate that efforts need to 
be made in order to build the representative VUV library, to the extent where it can properly support chemical assignment accuracy and confidence in the obtained result. Developing hybrid detection techniques, which involve parallel or in series coupling of several detection methods can offer a combination of advantages that cannot be attained by employing either of the techniques individually. Additionally, more advanced separation methods coupled with VUV detection can aid to fully exploit the potential of the technique.

Wider acceptance of the VUV technique in routine analysis is inhibited by the lack of standardized regulatory methods, but also higher cost when compared to FID or quadrupole MS. However, with the surge of standardized methods and further enrichment of the reference library it is expected that the analytical use of the VUV will increase.

\section{Vacuum ultraviolet spectroscopy coupling with comprehensive two-dimensional GC}

\subsection{Experimental}

Multidimensional gas chromatography (MDGC) was introduced as a means of reaching higher separation efficiency, necessary in the case of more complex samples analysis. Comprehensive $\mathrm{GC} \times \mathrm{GC}$, a type of MDGC, is characterized by a series of separations resulting in the entire sample being subjected to the analysis process. This methodology has signified a paradigm shift in the quality of chemical composition estimation and characterization of highly complex samples. Benefits of employing $\mathrm{GC} \times \mathrm{GC}$ separation are 
many. Claimed 4-5 times increase in sensitivity [72] and an order of magnitude larger peak capacity [73] compared to conventional 1D GC are the most cited benefits of the technique. For a deeper insight on $\mathrm{GC} \times \mathrm{GC}$, the reader can refer to numerous reviews of the $\mathrm{GC} \times \mathrm{GC}$ technique [74-87].

Owing to the fast ${ }^{2} \mathrm{D}$ separation which generates very narrow peaks $(50-600 \mathrm{~ms})$, the detectors employed for $\mathrm{GC} \times \mathrm{GC}$ must be characterized by a short rise time, small dispersion and high acquisition frequency $(20-100 \mathrm{~Hz})$. It is essential to collect sufficient number of data points across each ${ }^{2} \mathrm{D}$ peak for proper peak reconstruction, however oversampling ought to be avoided due to the large size of data acquired and greater noise levels [88]. $\mathrm{GC} \times \mathrm{GC}$ detectors should also have a wide dynamic range, and exhibit sensitivity and appropriate selectivity.

Detection systems which meet all of the above-mentioned criteria are for example single and triple quadrupole, time of flight, and quadrupole time of flight detectors. Currently, MS detection is most commonly applied across all $\mathrm{GC} \times \mathrm{GC}$ applications, however the use of MS comes with a large laboratory footprint owing to challenging data analysis. Other than mass spectrometry (MS), optical spectroscopic detectors are able to provide selective spectral information. However, until present, the application of optical spectroscopy technologies as universal detectors for $\mathrm{GC} \times \mathrm{GC}$ has been restricted mainly due to physical limitations such as insufficient acquisition speed (AED is for example limited to $10 \mathrm{~Hz}$ [89]) or high detection limits owing to small molecular absorption cross sections in the detection wavelength range [40]. Many of the limitations have been circumvented in the newly developed VUV detection system. The acquisition frequency can be up to $\sim 90 \mathrm{~Hz}$. Additionally, VUV-spectral data could be assumed to be orthogonal to typical GC-separation whereas some mass spectrometric information is highly related to the retention times of the molecules. Especially 
the molecular mass, one of the most selective information in $\mathrm{GC} \times \mathrm{GC} / \mathrm{MS}$, is highly related (non-orthogonal) to the elution order of the corresponding compound and becomes obvious for soft ionization techniques like photoionization [40]. If the information provided by the detection system is different from those that dictate the separation itself, in this case substantial complementary knowledge on sample features can be obtained. Further, the high peak capacity of the comprehensive separation systems along with the capabilities for mixture estimation of the VUV spectral signatures effectively increase the total number of species whose presence can be efficiently resolved [55].

Most important considerations regarding the use of the VUV detector in hyphenation with the $\mathrm{GC} \times \mathrm{GC}$ separation are related to the make-up gas pressure tuning. In $\mathrm{GC} \times \mathrm{GC}$, it is especially important to keep analyte diffusion in the VUV flow cell to minimum. As mentioned above, second dimension baseline peak widths in $\mathrm{GC} \times \mathrm{GC}$ are 50 to $600 \mathrm{~ms}$, hence using a detector with small internal volume is critical. In the VUV spectrometer, make-up gas tuning can be employed to decrease the residence time of the analyte in the volume of the flow cell. Gruber et al. [48] found in their study, that in VGA-100 which featured larger volume of the flow cell $(\sim 80 \mu 1)$ elevated make-up gas pressures of 1.5 psig and higher are necessary to maintain the peaks width $<600 \mathrm{~ms}$ for two-dimensional separation of breath gas metabolites. Second generation VUV spectrometer having lower volume of the flow cell does not require marked increase of the make-up gas pressure, hence sensitivity gain is incurred. High flows applied in the second dimension of the flow modulated $\mathrm{GC} \times \mathrm{GC}$ seem not to be an obstacle for efficient VUV detection [55], however upper limit of applicable flow has not been yet explored. 
As mentioned before, VUV is amenable to hyphenation to other detector types. Our studies and in-house obtained GC $\times$ GC-VUV chromatograms (Figure 9) have demonstrated very good results regarding the dual VUV-FID detection in the simple split mode for the flow modulated $\mathrm{GC} \times \mathrm{GC} .{ }^{2} \mathrm{D}$ baseline peak widths in the range up to $500 \mathrm{~ms}$ were obtained for both detection techniques. FID ability of quantitation of organic compounds combined with the qualitative information that VUV enables good insight into the global composition of petroleum samples.

\subsection{Data processing and analysis}

Processing of the $\mathrm{GC} \times \mathrm{GC}-\mathrm{VUV}$ data is specific to $\mathrm{GC} \times \mathrm{GC}$ applications. It generally begins with integrating an interval of a spectral band. This operation is called 'spectral filtering'. Further processing procedure can be reduced in a rather classic way to the following sequence of steps: baseline correction, detection of peaks corresponding to compounds of interest, and peaks integration [37,90]. In terms of baseline correction, there are several approaches in the literature that offer satisfactory solutions. We can cite, for instance, approaches by robust optimization of a parametric curve model that is forced to remain below the data [91], or morphological approach where the baseline is replaced more generally by a set of segments of various lengths [92]. These approaches are generally defined for curves, however the extension to $2 \mathrm{D}$ data is rather trivial, since data can be considered as a collection of side-by-side curves. 
Once the baseline has been corrected, a common way to quantify the data is to detect peak locations and then use integration areas defined by a mask that has been correctly aligned [37]. Detection of peaks of interest can be a difficult task. Approaches based on derivative calculation generally fail in the presence of low noise or coelutions. Local maxima detection, extremely well performing in image processing, gives a good answer for both 1D [92] and 2D data [93]. Before mask integration, mask alignment can be done using amer points and parametric deformation model defined for specific isolated compounds, or in a fully automatic way by a robust optimization and distance minimization [93]. Although robust, these calibration approaches are generally only effective in targeted cases, and it may be difficult to fully trust this type of approach in completely unknown cases. It is interesting to explore approaches without prior definition of a mask, simply with information on the positions of peaks of interest. The integration should automatically adapt to the morphology of the peaks present in the data, while respecting certain constraints (convexity, strict decrease from the apex). Here again, image processing could inspire some solutions particularly through developed segmentation algorithms, such as in reference [94] or in [83] which employs watershed. All these kind of tools that are available for classical $\mathrm{GC} \times \mathrm{GC}$ data still need to be developed for GC $\times$ GC-VUV data and adapted to the fact that the detector brings an additional dimension for separation.

Concerning softwares for processing and analysis of $\mathrm{GC} \times \mathrm{GC}-\mathrm{VUV}$ data, previous studies mainly rely on homemade Matlab software [40,48], GC Image [95] and ChromSquare [55]. GC Image is the only commercial software supporting direct import of the GC $\times$ GC-VUV data for two-dimensional visualization. For now, GC Image does not support functionalities of user friendly spectral filtering, or specific processing of GC $\times$ GC-VUV data. Recently 
introduced, free open-access plug im! software [96], proposes 3D visualization, spectral profile extraction, and spectral filtering for $\mathrm{GC} \times \mathrm{GC}-\mathrm{VUV}$ data. Additional functionalities such as noise filtering, baseline correction and signal integration are currently under study. A real perspective could be the possibility to directly visualize the initial $\mathrm{GC} \times \mathrm{GC}-\mathrm{VUV} 3 \mathrm{D}$ data. A first approach would be to focus on transposing quite directly baseline-correction and peak detection algorithms presented previously, and then to define 3D integration masks by non-connected sets, or defining 3D integration without prior mask. A second way would be to explore at each $\mathrm{GC} \times \mathrm{GC} 2 \mathrm{D}$ point mixture estimation in the VUV spectra, using reference spectra for each compound of interest. The problem then would become extremely complex to write and optimize, and machine learning, initially to accelerate convergence, would certainly be beneficial.

To conclude, there is clearly a need for adequate software with user friendly interface to manipulate such 3D complex data resulting from combining spectroscopy and chromatography, but also for advanced algorithms for baseline estimation, peak detections and quantitative integration.

\subsection{Comprehensive two-dimensional GC - Vacuum ultraviolet spectroscopy early applications}

First proof of concept study involved the VUV detection in combination with cryo-modulated $\mathrm{GC} \times \mathrm{GC}$ and was performed by Gröger and co-workers [40]. In this work, potential of the new detection technique for the analysis of diesel fuel and Fischer-Tropsch syncrude has 
been explored. Peak widths at mid-height in the range of $300 \mathrm{~ms}$ and LODs in low ng range were obtained. Spectral filters were employed to selectively detect specific families of compounds. 170-200 nm wavelength region was used to "filter out" compounds with aromatic $\pi \rightarrow \pi^{*}$ chromophores (Figure 10). Since isolated double bonds do not occur in fully processed and standardized middle distillate diesel (without FAMEs), the authors were able to assign the $\pi \rightarrow \pi^{*}$ transitions exclusively to the conjugated double bonds of aromatic structures. This can aid in often problematic differentiation between cyclic naphthenes and olefins in $\mathrm{GC} \times \mathrm{GC}$ separation of petroleum products. Authors found that the absorbance properties in the aromatics region $170-200 \mathrm{~nm}$ could also indicate the presence or absence of compounds containing oxygen.

The same group further investigated the ability of the cryo GC $\times$ GC-VUV to discriminate between isomeric compounds or isobaric species in hydrocarbon fuel and breath gas samples [48]. As in the previous study, they have shown that additional selectivity could be gained through the application of appropriate spectral filters. Especially small oxygenated breath metabolites demonstrated intense and characteristic absorption patterns. In the case of short chain fatty acids spectral features were demonstrated to become more distinct with decreased chain length and were dominated by high-energy $\sigma \rightarrow \sigma^{*}$ transitions. Results of the analysis were in agreement with $\mathrm{GC} \times \mathrm{GC}$-TOFMS findings demonstrating the potential of the technique.

Zoccali and co-workers [55] employed in their study for the first time flow modulated $\mathrm{GC} \times \mathrm{GC}$ in combination with VUV for the interrogation of bio-diesel fuel and fatty acids samples. Capabilities of the detection technique for the qualitative and quantitative analysis This article is protected by copyright. All rights reserved. 
(based on the pseudo-absolute quantification method) of investigated samples were evaluated. Peaks with good shape and $600 \mathrm{~ms}$ width at the base were obtained.

Chromatographic separation was satisfactory with the saturated, mono-aromatic, di-aromatic and tri-aromatic hydrocarbons well separated from each other, and from the FAMEs. Internal Standard-based Pseudo-absolute quantification of target analytes was performed by using the pre-recorded absorption cross-sections

Jennerwein et al. [97] recently demonstrated that combined capabilities of VUV and FID detection can provide for improved characterization of gasoline and middle distillates, especially olefins and diolefins. They pointed out the lack of software solutions for adequate treatment of the tridimensional GC $\times \mathrm{GC}$-VUV data.

Early studies have demonstrated that VUV detector is completely amenable to coupling with $\mathrm{GC} \times \mathrm{GC}$ in both cryo and flow modes and that its versatility and advantages which were observed trough GC-VUV applications can be exploited also in the comprehensive separations. Table 2 provides an overview of the current published works involving $\mathrm{GC} \times \mathrm{GC}$ VUV.

\section{Conclusion}

Informative broad band detection technology in the low end-UV range of the electromagnetic spectrum, which recently became commercially available, has allowed to access a domain of information which up to now was not easily attainable. Development of numerous 
applications involving GC-VUV but also arising of standardized methods testify the benefits of the provided information.

Spectral information provided is very featured for most of the species (even for small molecules and isomers), but also similar between the compounds belonging to the same family allowing spectral filtering tools to highlight specific chemical classes. Hence, target analysis but also group type analysis is a possibility. Classical requirements for chromatographic resolution can be decreased by the possibility to computationally discern spectral signatures of the species for which there is no temporal resolution through the application of automated mixture estimation algorithms. Applying the spectral mixture estimation approaches can enable fast and automated analysis, however the lack of the VUV absorption reference spectral libraries impedes broadening of the field of application for more complex samples, such as automated PIONA for heavier petroleum fractions. With the eminent advances in computation approaches, calculation of the theoretical spectra for compounds whose VUV absorption signatures are not currently available may bring additional power to the technique and eliminate the limitations imposed by the scarcity of reference spectral information in the low end-UV spectral range. From a quantitative point of view, detection limits up to a few ppm make the VUV amenable to a wide range of analytical challenges.

Finally, for the analysis of very complex mixtures of volatile and semi-volatile compounds, combination of $\mathrm{GC} \times \mathrm{GC}$ and VUV detection has been proven to be highly informative. Since this type of instrumental set-up is still not very widespread, more and more studies ought to be devoted to this topic in the coming years, leading to potentially fast, detailed and This article is protected by copyright. All rights reserved. 


\section{References}

[1] Watson, N. E., Bahaghighat, H. D., Cui, K., Synovec, R. E., Comprehensive ThreeDimensional Gas Chromatography with Time-of-Flight Mass Spectrometry. Anal. Chem. 2017, 89, 1793-1800.

[2] Santos, I. C., Schug, K. A., Recent advances and applications of gas chromatography vacuum ultraviolet spectroscopy. J. Sep. Sci. 2017, 40, 138-151.

[3] Internal Standard ISO 21348, Space Environment (Natural and Artificial) — Process for Determining Solar Irradiances. 2007.

[4] Skoog, D. A., Holler, F. J., Crouch, S. R., Principles of Instrumental Analysis. Brooks Cole 2006.

[5] Schug, K. A., Sawicki, I., Carlton, D. D., Fan, H., McNair, H. M., Nimmo, J. P., Kroll, P., Smuts, J., Walsh, P., Harrison, D., Vacuum ultraviolet detector for gas chromatography. Anal. Chem. 2014, 86, 8329-8335.

[6] Hanley, L., Zimmermann, R., Light and molecular ions: The emergence of vacuum UV single-photon ionization in MS. Anal. Chem. 2009, 81, 4174-4182.

[7] Li, D. X., Gan, L., Bronja, A., Schmitz, O. J., Gas chromatography coupled to atmospheric pressure ionization mass spectrometry (GC-API-MS): Review. Anal. Chim. Acta 2015, 891, 43-61.

[8] Anthony, I. G. M., Brantley, M. R., Gaw, C. A., Floyd, A. R., Solouki, T., Vacuum Ultraviolet Spectroscopy and Mass Spectrometry: A Tandem Detection Approach for Improved Identification of Gas Chromatography-Eluting Compounds. Anal. Chem. 
$2018,90,4878-4885$.

[9] Ozaki, Y., Morisawa, Y., Ikehata, A., Higashi, N., Far-ultraviolet spectroscopy in the solid and liquid states: A review. Appl. Spectrosc. 2012, 66, 1-25.

[10] Ozaki, Y., Kawata, S., Far-and Deep-Ultraviolet Spectroscopy. 2015.

[11] Mao, J. X., Kroll, P., Schug, K. A., Vacuum ultraviolet absorbance of alkanes: an experimental and theoretical investigation. Struct. Chem. 2019, DOI: 10.1007/s11224019-01412-y.

[12] Skultety, L., Frycak, P., Qiu, C., Smuts, J., Shear-Laude, L., Lemr, K., Mao, J. X., Kroll, P., Schug, K. A., Szewczak, A., Vaught, C., Lurie, I., Havlicek, V., Resolution of isomeric new designer stimulants using gas chromatography - Vacuum ultraviolet spectroscopy and theoretical computations. Anal. Chim. Acta 2017, 971, 55-67.

[13] Fan, H., Smuts, J., Bai, L., Walsh, P., Armstrong, D. W., Schug, K. A., Gas chromatography-vacuum ultraviolet spectroscopy for analysis of fatty acid methyl esters. Food Chem. 2016, 194, 265-271.

[14] Bai, L., Smuts, J., Walsh, P., Fan, H., Hildenbrand, Z., Wong, D., Wetz, D., Schug, K. A., Permanent gas analysis using gas chromatography with vacuum ultraviolet detection. J. Chromatogr. A 2015, 1388, 244-250.

[15] Fan, H., Smuts, J., Walsh, P., Harrison, D., Schug, K. A., Gas chromatographyvacuum ultraviolet spectroscopy for multiclass pesticide identification. J. Chromatogr. A 2015, 1389, 120-127.

[16] Weatherly, C. A., Zhang, Y., Smuts, J. P., Fan, H., Xu, C., Schug, K. A., Lang, J. C., Armstrong, D. W., Analysis of Long-Chain Unsaturated Fatty Acids by Ionic Liquid 
Gas Chromatography. J. Agric. Food Chem. 2016, 64, 1422-1432.

[17] Schenk, J., Mao, J. X., Smuts, J., Walsh, P., Kroll, P., Schug, K. A., Analysis and deconvolution of dimethylnaphthalene isomers using gas chromatography vacuum ultraviolet spectroscopy and theoretical computations. Anal. Chim. Acta 2016, 945, 18.

[18] Schenk, J., Nagy, G., Pohl, N. L. B., Leghissa, A., Smuts, J., Schug, K. A., Identification and deconvolution of carbohydrates with gas chromatography-vacuum ultraviolet spectroscopy. J. Chromatogr. A 2017, 1513, 210-221.

[19] Pechancová, R., Qiu, C., Smuts, J., Lemr, K., Schug, K. A., Comparative study of ink photoinitiators in food packages using gas chromatography with vacuum ultraviolet detection and gas chromatography with mass spectrometry. J. Sep. Sci. 2019, 42, 556565.

[20] Reiss, R., Gruber, B., Klingbeil, S., Gröger, T., Ehlert, S., Zimmermann, R., Evaluation and application of gas chromatography - vacuum ultraviolet spectroscopy for drug- and explosive precursors and examination of non-negative matrix factorization for deconvolution. Spectrochim. Acta Part A Mol. Biomol. Spectrosc. 2019, 219, 129-134.

[21] Qiu, C., Smuts, J., Schug, K. A., Analysis of terpenes and turpentines using gas chromatography with vacuum ultraviolet detection. J. Sep. Sci. 2017, 40, 869-877.

[22] Buchalter, S., Marginean, I., Yohannan, J., Lurie, I. S., Gas chromatography with tandem cold electron ionization mass spectrometric detection and vacuum ultraviolet detection for the comprehensive analysis of fentanyl analogues. J. Chromatogr. A 2019, 1596, 183-193.

This article is protected by copyright. All rights reserved. 
[23] García-Cicourel, A. R., Janssen, H. G., Direct analysis of aromatic hydrocarbons in purified mineral oils for foods and cosmetics applications using gas chromatography with vacuum ultraviolet detection. J. Chromatogr. A 2019, 1-8.

[24] Bai, L., Smuts, J., Walsh, P., Qiu, C., McNair, H. M., Schug, K. A., Pseudo-absolute quantitative analysis using gas chromatography - Vacuum ultraviolet spectroscopy - A tutorial. Anal. Chim. Acta 2017, 953, 10-22.

[25] Walsh, P., Garbalena, M., Schug, K. A., Rapid Analysis and Time Interval Deconvolution for Comprehensive Fuel Compound Group Classification and Speciation Using Gas Chromatography-Vacuum Ultraviolet Spectroscopy. Anal. Chem. 2016, 88, 11130-11138.

[26] Suendo, V., Viridi, S., Ab Initio Calculation of UV-Vis Absorption Spectra of a Single Molecule Chlorophyll a: Comparison Study between RHF/CIS, TDDFT, and SemiEmpirical Methods. ITB J. Sci. 2012, 44, 93-112.

[27] Schug, K. A., Leghissa, A., Smuts, J., Ponduru, T. T., Dias, H. V. R., Mao, J. X., Qiu, C., Copper( i )-based oxidation of polycyclic aromatic hydrocarbons and product elucidation using vacuum ultraviolet spectroscopy and theoretical spectral calculations . New J. Chem. 2018, 42, 19442-19449.

[28] Mao, J. X., Walsh, P., Kroll, P., Schug, K. A., Simulation of Vacuum Ultraviolet Absorption Spectra: Paraffin, Isoparaffin, Olefin, Naphthene, and Aromatic Hydrocarbon Class Compounds. Appl. Spectrosc. 2019, 0, 3702819875132.

[29] Jalali-Heravi, M., Parastar, H., Assessment of the co-elution problem in gas chromatography-mass spectrometry using non-linear optimization techniques. Chemom. Intell. Lab. Syst. 2010, 101, 1-13. 
[30] Schug, K. A., The Complementarity of Vacuum Ultraviolet Spectroscopy and Mass Spectrometry for Gas Chromatography Detection. LCGC 2017, 35, 511-512.

[31] Lagesson-Andrasko, L., Lagesson, V., Andrasko, J., The Use of Gas-Phase UV Spectra in the 168-330-nm Wavelength Region for Analytical Purposes. 1. Qualitative Measurements. Anal. Chem. 1998, 70, 819-826.

[32] Lagesson, V., Micro Gas Chromatographic Separation Combined with UV- and IRSpectrophotometric Detection/Identification with Applications within the Occupational Hygiene Field Using Diffusive and Active Sampling Followed by a Direct Thermal Desorption Technique, University of Gothenburg, 1992.

[33] van Stee, L. L. P., Brinkman, U. A. T., Developments in the application of gas chromatography with atomic emission (plus mass spectrometric) detection. $J$. Chromatogr. A 2008, 1186, 109-122.

[34] Albro, T. G., Dreifuss, P. A., Quantitative Determination of Sulfur Compounds in FCC Gasolines by AED. J. High Resolut. Chromatogr. 1993, 13-17.

[35] González, A. M., Uden, P. C., Optimization and evaluation of atomic emission gas chromatographic detection for nitrogen using the $388 \mathrm{~nm}$ molecular emission spectral band. J. Chromatogr. A 2000, 898, 201-210.

[36] Franck, B., Caractérisation Des Distillats Pétroliers Par Couplage Chromatographie En Phase Gazeuse et Détection Par Émission Atomique, Université Claude Bernard Lyon $1,1997$.

[37] Bertoncini, F., Courtiade-Tholance, M., Thiébaut, D., Gas Chromatography and 2DGas Chromatography for Petroleum Industry: The Race for Selectivity. Editions 
TECHNIP 2013.

[38] Kaye, W., Far-Ultraviolet Spectroscopic Detection of Gas Chromatograph Effluent. Anal. Chem. 1962, 34, 287-293.

[39] Gras, R., Luong, J., Shellie, R. A., Miniaturized micromachined gas chromatography with universal and selective detectors for targeted volatile compounds analysis $\leftleftarrows . J$. Chromatogr. A 2018, 1573, 151-155.

[40] Gröger, T., Gruber, B., Harrison, D., Saraji-Bozorgzad, M., Mthembu, M., Sutherland, A., Zimmermann, R., A Vacuum Ultraviolet Absorption Array Spectrometer as a Selective Detector for Comprehensive Two-Dimensional Gas Chromatography: Concept and First Results. Anal. Chem. 2016, 88, 3031-3039.

[41] Kaye, W., Waska, F., A Rapid-Scan Far Ultraviolet Spectrophotometer for Monitoring Gas Chromatograph Effluent. Anal. Chem. 1964, 36, 2380-2381.

[42] Publishers, E. S., Driscoll, J. N., Duffy, M., Pappas, S., Capillary gas chromatographic absorbance detector analysis with the far-uv. 1988, 1.

[43] Wickramaaratchi, M. A., Premuzic, E. T., Lin, M., Snyder, P. A., Circular dichroism detection of optically active compounds in gas chromatography using vacuum ultraviolet synchrotron radiation. J. Chromatogr. A 1987, 390, 413-420.

[44] Ishii, T., Historical Survey and New Opportunities in the VUV. J. Synchrotron Radiat. 1994, 1, 95-100.

[45] Driscoll, J. N., in: Hill, H. H., McMinn, D. G. (Eds.), Detectors for Capillary Chromatography. Wiley 1992.

[46] Driscoll, J. N., Photodiode U.S. Patent, US-4614871-A, publ. date 1986. 
[47] Canfield, L. R., Swanson, N., Far Ultraviolet Detector Standards. Nbs Sp 250-2 1987, $92,87-112$.

[48] Gruber, B., Groeger, T., Harrison, D., Zimmermann, R., Vacuum ultraviolet absorption spectroscopy in combination with comprehensive two-dimensional gas chromatography for the monitoring of volatile organic compounds in breath gas: A feasibility study. J. Chromatogr. A 2016, 1464, 141-146.

[49] Halász, I., Concentration and Mass Flow Rate Sensitive Detectors in Gas Chromatography. Anal. Chem. 1964, 36, 1428-1430.

[50] Dunkle, M. N., Pijcke, P., Winniford, B., Bellos, G., Quantification of the composition of liquid hydrocarbon streams: Comparing the GC-VUV to DHA and GCxGC. $J$. Chromatogr. A 2019, 1587, 239-246.

[51] Liu, H., Raffin, G., Trutt, G., Randon, J., Is vacuum ultraviolet detector a concentration or a mass dependent detector? J. Chromatogr. A 2017, 1530, 171-175.

[52] Weber, B. M., Walsh, P., Harynuk, J. J., Determination of Hydrocarbon Group-Type of Diesel Fuels by Gas Chromatography with Vacuum Ultraviolet Detection. Anal. Chem. 2016, 88, 5809-5817.

[53] Schug, K. A., Smuts, J., Santos, I. C., Crawford, M. L., Grant, R. P., Large-volume injection gas chromatography-vacuum ultraviolet spectroscopy for the qualitative and quantitative analysis of fatty acids in blood plasma. Anal. Chim. Acta 2018, 1053, 169177.

[54] Anthony, I. G. M., Brantley, M. R., Floyd, A. R., Gaw, C. A., Solouki, T., Improving Accuracy and Confidence of Chemical Identification by Gas Chromatography/Vacuum 
Ultraviolet Spectroscopy-Mass Spectrometry: Parallel Gas Chromatography, Vacuum Ultraviolet, and Mass Spectrometry Library Searches. Anal. Chem. 2018, 90, 1230712313.

[55] Zoccali, M., Schug, K. A., Walsh, P., Smuts, J., Mondello, L., Flow-modulated comprehensive two-dimensional gas chromatography combined with a vacuum ultraviolet detector for the analysis of complex mixtures. J. Chromatogr. A 2017, $1497,135-143$.

[56] Qiu, C., Cochran, J., Smuts, J., Walsh, P., Schug, K. A., Gas chromatography-vacuum ultraviolet detection for classification and speciation of polychlorinated biphenyls in industrial mixtures. J. Chromatogr. A 2017, 1490, 191-200.

[57] Leghissa, A., Smuts, J., Qiu, C., Hildenbrand, Z. L., Schug, K. A., Detection of cannabinoids and cannabinoid metabolites using gas chromatography with vacuum ultraviolet spectroscopy. Sep. Sci. Plus 2018, 1, 37-42.

[58] Liu, H., Raffin, G., Trutt, G., Dugas, V., Demesmay, C., Randon, J., Hyphenation of short monolithic silica capillary column with vacuum ultraviolet spectroscopy detector for light hydrocarbons separation. J. Chromatogr. A 2019, DOI:

10.1016/j.chroma.2019.02.033.

[59] ASTM D8071-17, Standard Test Method for Determination of Hydrocarbon Group Types and Select Hydrocarbon and Oxygenate Compounds in Automotive SparkIgnition Engine Fuel Using Gas Chromatography with Vacuum Ultraviolet Absorption Spectroscopy Detection, www.astm.org.

[60] ASTM WK66576 New Test Method for Determination of Saturated Hydrocarbon, Aromatic and Di-aromatic Content of Aviation Turbine Fuels Using Gas 
Chromatography with Vacuum Ultraviolet Absorption Spectroscopy Detection, www.astm.org.

[61] Weston, C., Smuts, J., Mao, J. X., Schug, K. A., Investigation of gas phase absorption spectral similarity for stable-isotopically labeled compounds in the $125-240 \mathrm{~nm}$ wavelength range. Talanta 2018, 177, 41-46.

[62] Warar S., Anthony I.G.M., Gaw C.A., S. T., Populating a Vacuum Ultraviolet Spectroscopy Library using Tandem GC/VUV-MS and Chemometric Deconvolution of Real-World Sample Data (Poster). ASMS, Atlanta, GA 2019.

[63] Bai, L., Smuts, J., Schenk, J., Cochran, J., Schug, K. A., Comparison of GC-VUV, GC-FID, and comprehensive two-dimensional GC-MS for the characterization of weathered and unweathered diesel fuels. Fuel 2018, 214, 521-527.

[64] Schenk, J., Carlton, D. D., Smuts, J., Cochran, J., Shear, L., Hanna, T., Durham, D., Cooper, C., Schug, K. A., Lab-simulated downhole leaching of formaldehyde from proppants by high performance liquid chromatography (HPLC), headspace gas chromatography-vacuum ultraviolet (HS-GC-VUV) spectroscopy, and headspace gas chromatography-mass spectrometry (HS-GC-MS). Environ. Sci. Process. Impacts $2019,21,214-223$.

[65] Muthal, A. P., Study of Selectivity in Extraction, Separation and Detection on Drugs Using Gas Chromatography, Seton Hall University, 2017.

[66] Zheng, J., Huang, C., Wang, S., Challenging pharmaceutical analyses by gas chromatography with vacuum ultraviolet detection. J. Chromatogr. A 2018, 1567, $185-190$. 
[67] Cruse, C. A., Goodpaster, J. V., Generating highly specific spectra and identifying thermal decomposition products via Gas Chromatography / Vacuum Ultraviolet Spectroscopy (GC/VUV): Application to nitrate ester explosives. Talanta 2019, 195, $580-586$.

[68] Roberson, Z. R., Goodpaster, J. V., Differentiation of structurally similar phenethylamines via gas chromatography-vacuum ultraviolet spectroscopy $(\mathrm{GC}-$ VUV). Forensic Chem. 2019, 15, 100172.

[69] Santos, I. C., Smuts, J., Choi, W. S., Kim, Y., Kim, S. B., Schug, K. A., Analysis of bacterial FAMEs using gas chromatography - vacuum ultraviolet spectroscopy for the identification and discrimination of bacteria. Talanta 2018, 182, 536-543.

[70] Santos, I. C., Chaumette, A., Smuts, J., Hildenbrand, Z. L., Schug, K. A., Analysis of bacteria stress responses to contaminants derived from shale energy extraction. Environ. Sci. Process. Impacts 2019, 21, 269-278.

[71] Shear-Laude, L., Gas Chromatography-Vacuum Ultraviolet Absorbance Spectroscopy for the Quantitative Determination of Trace and Bulk Water in Organic Solvents. LCGC 2017, 13, 9-13.

[72] Lee, A. L., Bartle, K. D., Lewis, A. C., A model of peak amplitude enhancement in orthogonal two-dimensional gas chromatography. Anal. Chem. 2001, 73, 1330-1335.

[73] Blumberg, L. M., Comprehensive two-dimensional gas chromatography: metrics, potentials, limits. J. Chromatogr. A 2003, 985, 29-38.

[74] Phillips, J. B., Beens, J., Comprehensive two-dimensional gas chromatography: a hyphenated method with strong coupling between the two dimensions. J. Chromatogr. 
A 1999, 856, 331-347.

[75] Dallüge, J., Beens, J., Brinkman, U. A. T., Comprehensive two-dimensional gas chromatography: A powerful and versatile analytical tool. J. Chromatogr. A 2003, 1000, 69-108.

[76] Edwards, M., Boswell, H., Górecki, T., Comprehensive Multidimensional Chromatography. Curr. Chromatogr. 2015, 2, 80-109.

[77] Fernandez, X., Filippi, J.-J., Jeanville, M., Chromatographie en phase gazeuse à deux dimensions : GC-GC et GCxGC. Doss. les Tech. l'ingénieur 2011, 33.

[78] Prebihalo, S. E., Berrier, K. L., Freye, C. E., Bahaghighat, H. D., Moore, N. R., Pinkerton, D. K., Synovec, R. E., Multidimensional Gas Chromatography: Advances in Instrumentation, Chemometrics, and Applications. Anal. Chem. 2018, 90, 505-532.

[79] Pollo, B. J., Alexandrino, G. L., Augusto, F., Hantao, L. W., The impact of comprehensive two-dimensional gas chromatography on oil \& gas analysis: Recent advances and applications in petroleum industry. TrAC - Trends Anal. Chem. 2018, $105,202-217$

[80] Beens, J., Comprehensive two-dimensional gas chromatography — a powerful and versatile technique. $2005,123-127$.

[81] Adahchour, M., Beens, J., Brinkman, U. A. T., Recent developments in the application of comprehensive two-dimensional gas chromatography. J. Chromatogr. A 2008, $1186,67-108$.

[82] Edwards, M., Mostafa, A., Górecki, T., Modulation in comprehensive two-dimensional gas chromatography: 20 years of innovation. Anal. Bioanal. Chem. 2011, 401, 2335- 
2349.

[83] Nizio, K. D., McGinitie, T. M., Harynuk, J. J., Comprehensive multidimensional separations for the analysis of petroleum. J. Chromatogr. A 2012, 1255, 12-23.

[84] Seeley, J. V., Recent advances in flow-controlled multidimensional gas chromatography. J. Chromatogr. A 2012, 1255, 24-37.

[85] Meinert, C., Meierhenrich, U. J., A new dimension in separation science: Comprehensive two-dimensional gas chromatography. Angew. Chemie - Int. Ed. 2012, $51,10460-10470$.

[86] Mostafa, A., Edwards, M., Górecki, T., Optimization aspects of comprehensive twodimensional gas chromatography. J. Chromatogr. A 2012, 1255, 38-55.

[87] Seeley, J. V., Seeley, S. K., Multidimensional gas chromatography: Fundamental advances and new applications. Anal. Chem. 2013, 85, 557-578.

[88] Ong, R., Marriott, P., Morrison, P., Haglund, P., Influence of chromatographic conditions on separation in comprehensive gas chromatography. J. Chromatogr. A $2002,962,135-152$.

[89] van Stee, L. L. P., Beens, J., Vreuls, R. J. J., Brinkman, U. A. T., Comprehensive twodimensional gas chromatography with atomic emission detection and correlation with mass spectrometric detection: Principles and application in petrochemical analysis. $J$. Chromatogr. A 2003, 1019, 89-99.

[90] Pierce, K. M., Kehimkar, B., Marney, L. C., Hoggard, J. C., Synovec, R. E., Review of chemometric analysis techniques for comprehensive two dimensional separations data. J. Chromatogr. A 2012, 1255, 3-11. 
[91] Ning, X., Selesnick, I. W., Duval, L., Chromatogram baseline estimation and denoising using sparsity (BEADS). Chemom. Intell. Lab. Syst. 2014, 139, 156-167.

[92] Celse, B., Moreaud, M., Duval, L., Cavagnino, D., Gas Chromatography and 2D-Gas Chromatography for Petroleum Industry. The Race for Selectivity. Editions TECHNIP 2013, pp. 99-151.

[93] Couprie, C., Duval, L., Moreaud, M., Hénon, S., Tebib, M., Souchon, V., BARCHAN: Blob Alignment for Robust CHromatographic ANalysis. J. Chromatogr. A 2017, 1484, $65-72$.

[94] Latha, I., Reichenbach, S. E., Tao, Q., Comparative analysis of peak-detection techniques for comprehensive two-dimensional chromatography. J. Chromatogr. A $2011,1218,6792-6798$.

[95] GC Image: Software for Multidimensional Chromatography, https://www.gcimage.com/index.html.

[96] “plugim!" an open access and customizable software for signal and image processing, https://www.plugim.fr.

[97] Jennerwein, K. M., Eschner, M., Wilharm, T., Application of GCxGC-VUV and GCxGC-FID for the analysis of common gasoline samples, middle distillates and crude oil distillation cuts. PEFTEC 2019 Poster 2019.

[98] Sweet, R. M., in: R.M., S., A.D., W. (Eds.), Synchrotron Radiation in Structural Biology. Springer US, Boston, MA 1989, pp. 63-66.

\section{Figure Captions}

This article is protected by copyright. All rights reserved. 
Fig. 1 Absorption spectrum of water from IR to low-UV region. Reprinted with permission from [10] Copyright (2015) Springer Nature.

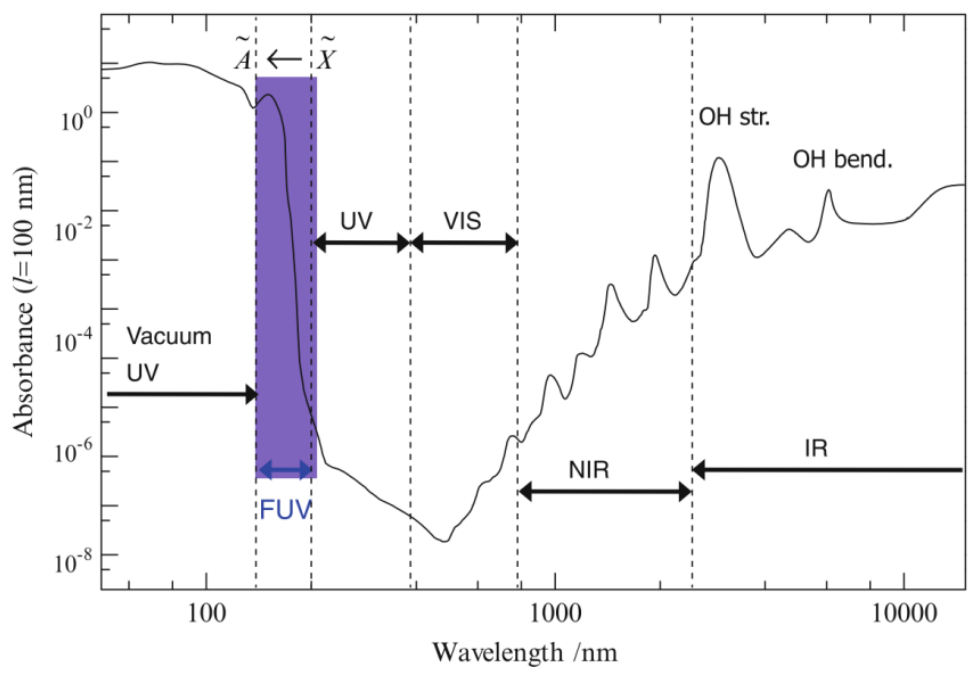

Fig. 2 Normalized VUV spectra for selected hydrocarbons. Reprinted with permission from [63] Copyright (2018) Elsevier.

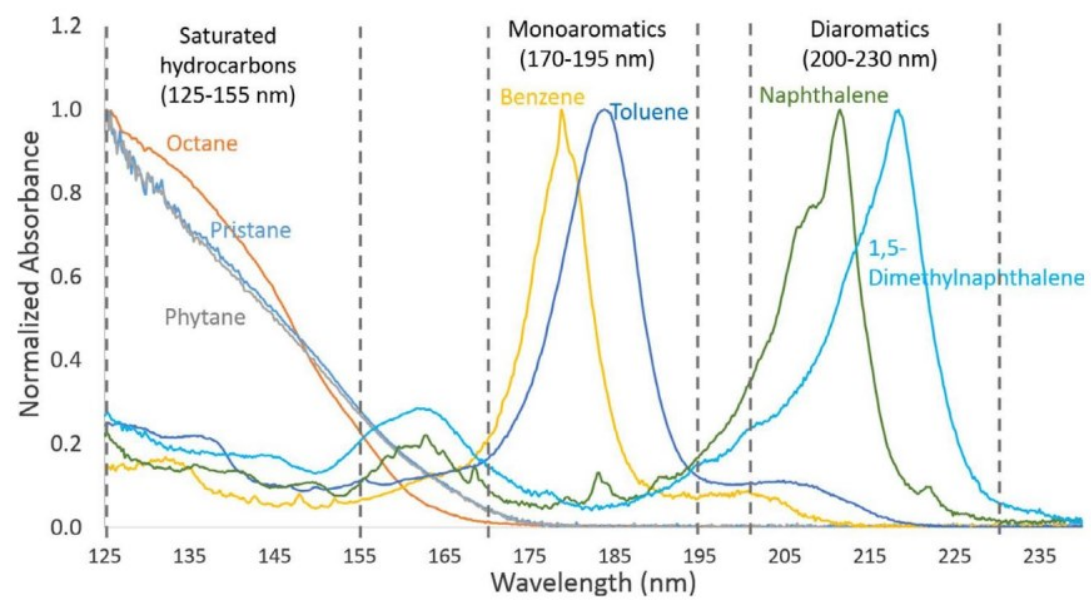

Fig. 3 VUV library (blue), experimental (orange) and theoretical (green) VUV spectra for anthracene and 9,10-anthraquinone. Reprinted with permission from [27] Copyright (2018) Royal Society of Chemistry. 


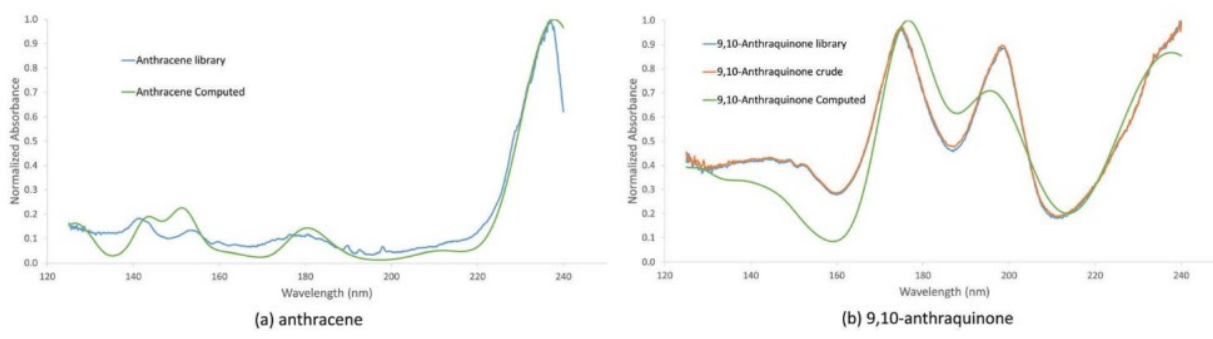

Fig. 4 Timelines highlighting research directions in the development of the GC-VUV technology. Red arrows indicate the introduction of the first research paper on new broad band VUV detector and the first proposed ASTM method involving novel detector. Figures reprinted with permission: from [5] Copyright (2014) American Chemical Society; from [8] Copyright (2014) American Chemical Society; from [31] Copyright (1998) American Chemical Society; from [40] Copyright (2016) American Chemical Society; from [98] Copyright (1989) Springer Nature.

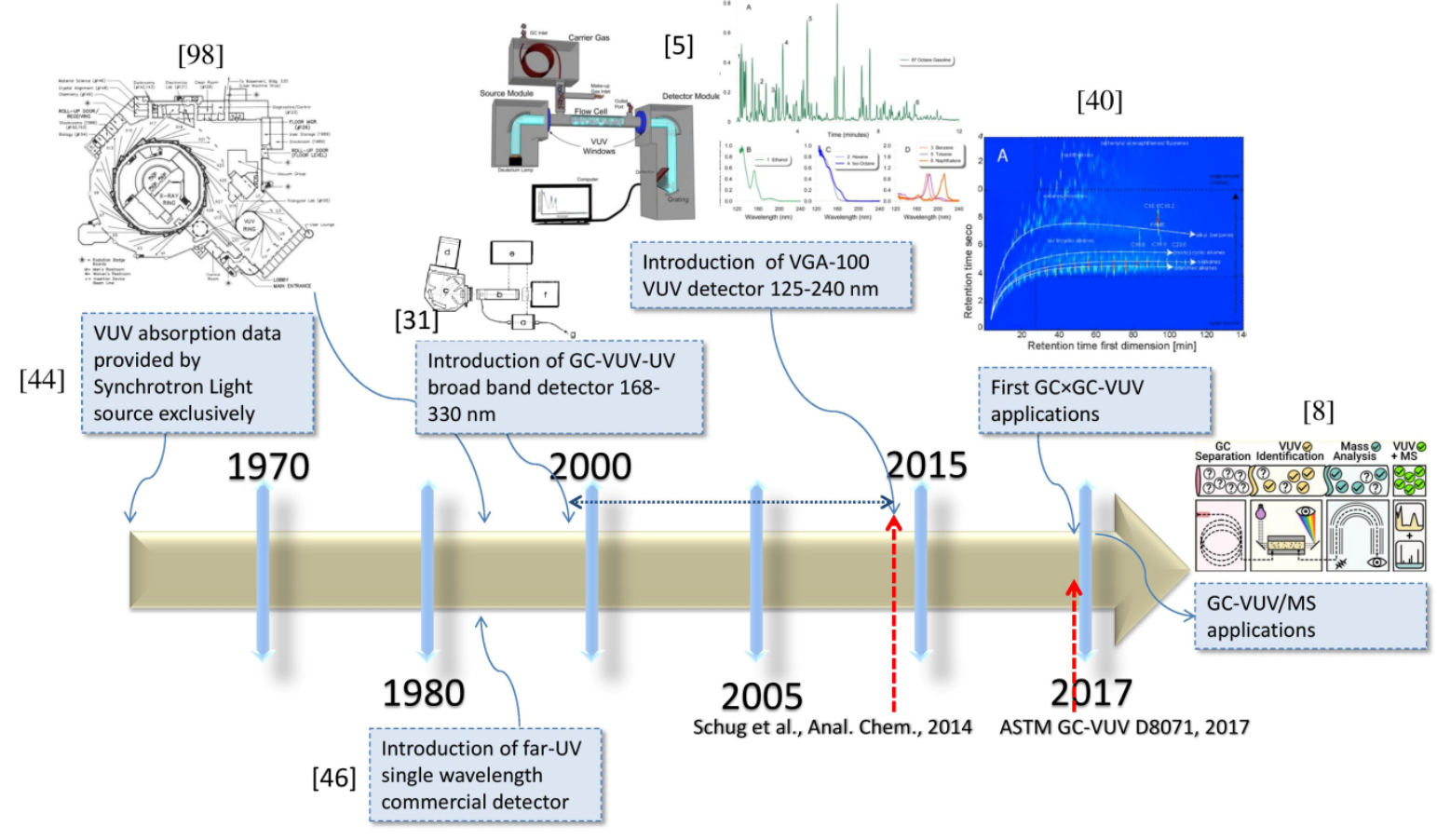

This article is protected by copyright. All rights reserved. 
Fig. 5 Mixture spectra over time represented as a product of a concentration profile matrix and a matrix of spectral features for each of the compounds.

Mixture spectra

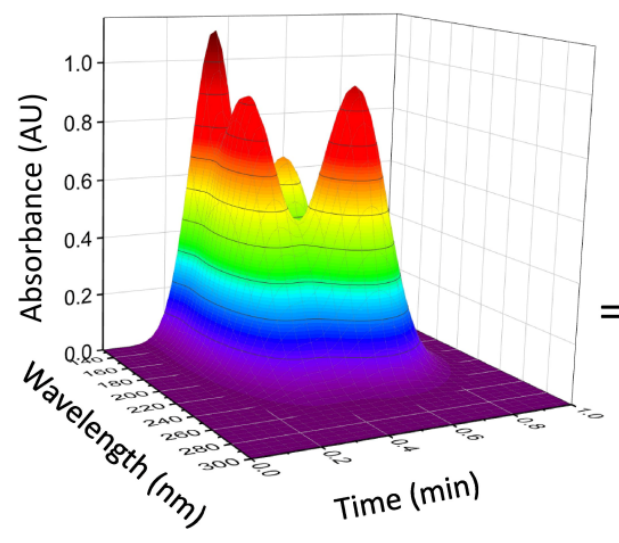

Physical model

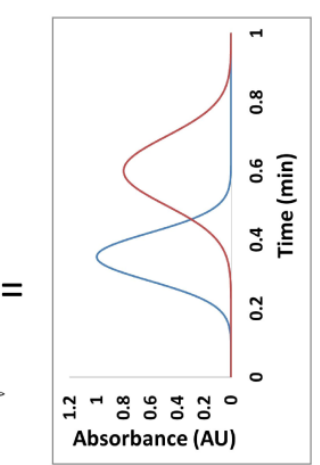

$\mathrm{X}$

$$
\mathbf{A}=\mathbf{C} \quad \mathrm{x} \quad \mathbf{P}
$$

(data matrix) (concentration) $\mathrm{x}$ (spectra)

Fig. 6 Estimation of cyclandelate and safrole via spectral mixture estimation (dotdashed line) and NMF (dotted line) from an original sample. B) Estimation of 3-nitrophenol and 2,6-DNT via mixture estimation (dotdashed line) and NMF (dotted line). Reprinted with permission from [20] Copyright (2019) Elsevier.
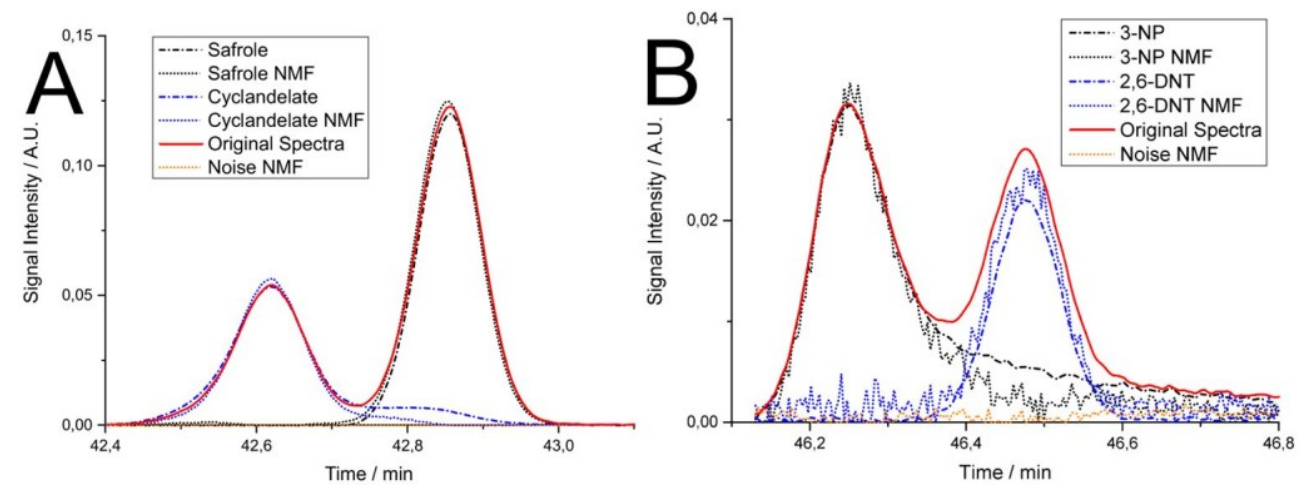

This article is protected by copyright. All rights reserved. 
Fig. 7 Chromatograms with applied spectral filters for GC-VUV analysis of (A) unweathered, (B) $25 \%$ weathered, (C) $50 \%$ weathered, and (D) $75 \%$ weathered diesel fuels. The weathered diesel fuels were artificially weathered by evaporation. Reprinted with permission from [63] Copyright (2018) Elsevier.
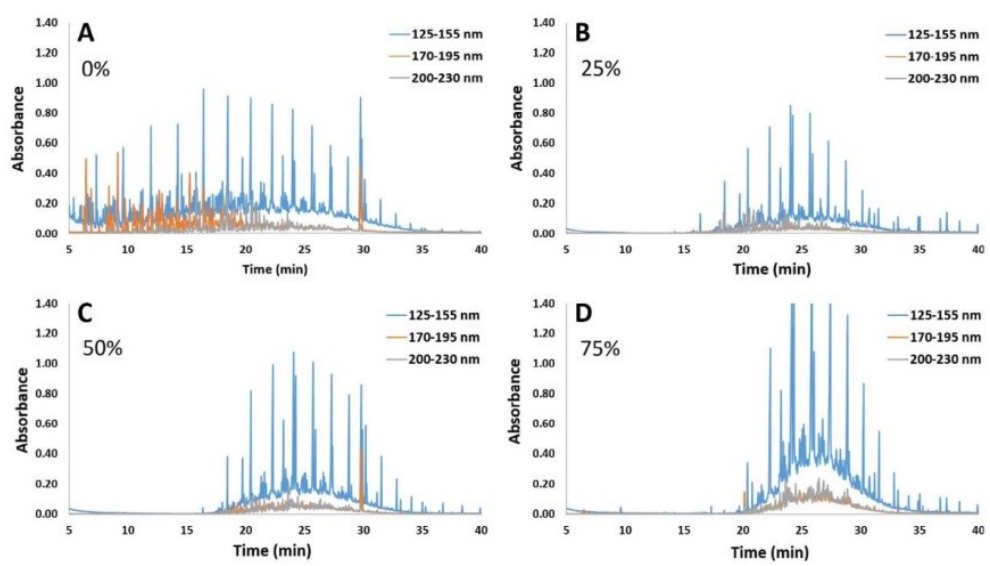

Fig. 8 Zoomed region illustrating olefin misidentification for liquid hydrocarbon stream 2: A) DHA and B) GC-VUV (deconvolution). Reprinted with permission from [50] Copyright (2019) Elsevier.

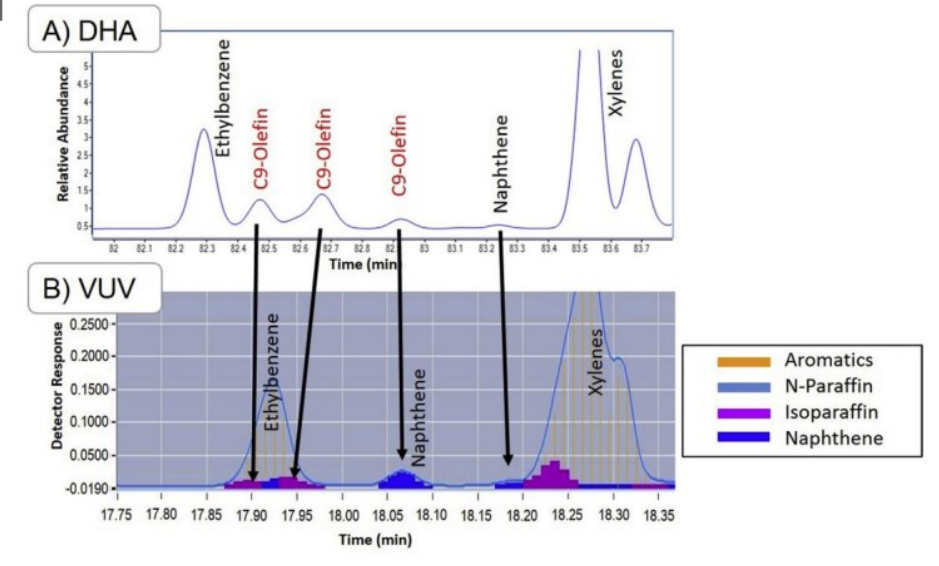


Fig. 9 Application of GC $\times$ GC-VUV/FID in the split mode for the analysis of petroleum middle distillates: (A) GC $\times$ GC-FID and (B) GC $\times$ GC-VUV chromatograms of the investigated Gas Oil (Total absorption at 125-240 nm).
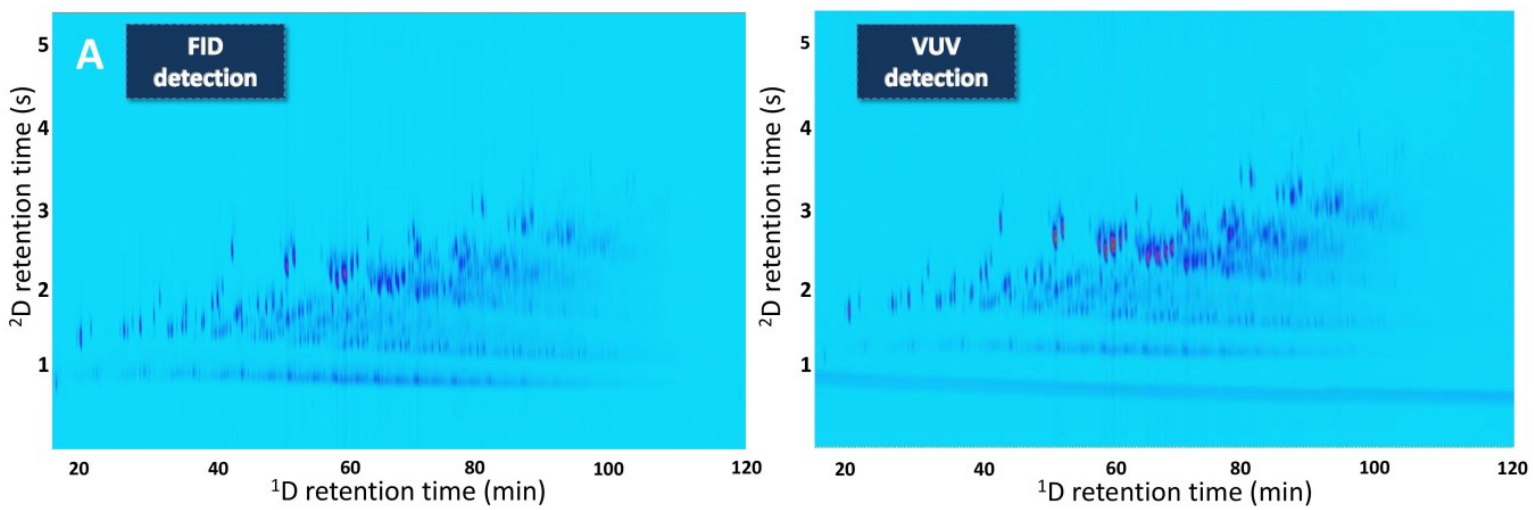

Fig. 10 Application of spectral filters for different petrochemical matrixes. (A) GC $\times$ GC-VUV chromatogram of a diesel fuel (total VUV-absorption 125-240 nm). (B) Application of 170$200 \mathrm{~nm}$ filter to (A) for the discrimination of $\pi^{*} \leftarrow \pi$ chromophores. Reprinted with permission from [40] Copyright (2016) American Chemical Society.
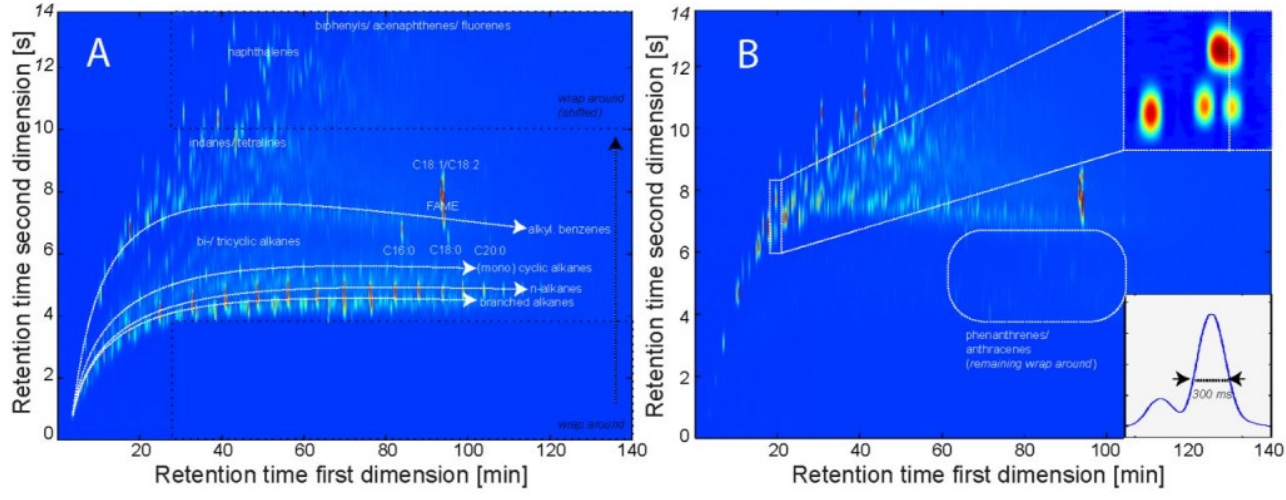

This article is protected by copyright. All rights reserved. 
Table Captions

Table 1 Overview of the GC-VUV applications.

\begin{tabular}{|c|c|c|c|c|c|c|c|}
\hline $\begin{array}{l}\text { App. } \\
\text { Field }\end{array}$ & Reference & GC & VUV & $\begin{array}{c}\text { Sample } \\
\text { type }\end{array}$ & LODs & $\begin{array}{c}\text { VUV } \\
\text { advantages }\end{array}$ & $\begin{array}{c}\text { VUV } \\
\text { limitations }\end{array}$ \\
\hline \multirow{8}{*}{$\begin{array}{l}0 \\
0 \\
0 \\
0 \\
\\
0\end{array}$} & $\begin{array}{l}\text { Schug et al. [5], } \\
2014\end{array}$ & $\begin{array}{c}\text { SGE BPX-5 } \\
(14 \mathrm{~m} \times \\
250 \mu \mathrm{m} \times \\
0.25 \mu \mathrm{m}) \\
\text { Rxi-1 MS } \\
(30 \mathrm{~m} \times \\
250 \mu \mathrm{m} \times \\
0.25 \mu \mathrm{m}) \\
\text { ZB-5 } \\
(15 \mathrm{~m} \times \\
250 \mu \mathrm{m} \times \\
0.5 \mu \mathrm{m})\end{array}$ & $\begin{array}{l}\text { VGA- } \\
100 \\
2.5-10 \\
\mathrm{~Hz}\end{array}$ & $\begin{array}{l}\text { Hydrocarbons, } \\
\text { fixed gases, } \\
\text { polyaromatic } \\
\text { hydrocarbons, } \\
\text { fatty acids, } \\
\text { pesticides, drugs, } \\
\text { and estrogens }\end{array}$ & $\begin{array}{c}\text { low to mid } \\
\text { ppb }\end{array}$ & $\begin{array}{l}\text { Universal detection, } \\
\text { elaborate spectral } \\
\text { features even for } \\
\text { isomers; Spectral } \\
\text { mixture estimation }\end{array}$ & $\begin{array}{l}\text { Similar spectral } \\
\text { features for } \\
\text { homologues }\end{array}$ \\
\hline & $\begin{array}{l}\text { Bai et al. [14], } \\
2015\end{array}$ & $\begin{array}{l}\text { HP PLOT/Q } \\
\begin{array}{c}(30 \mathrm{~m} \times \\
0.32 \mathrm{~mm} \times \\
20 \mu \mathrm{m})\end{array}\end{array}$ & $\begin{array}{l}\text { VGA- } \\
100 \\
10 \mathrm{~Hz} \\
0.25 \\
\text { psi }\end{array}$ & $\begin{array}{l}\text { Natural gas in } \\
\text { drinking water, } \\
\text { thermal } \\
\text { decomposition } \\
\text { products of Li- } \\
\text { batteries }\end{array}$ & & $\begin{array}{l}\text { Small molecules } \\
\text { exhibit elaborate } \\
\text { spectral features; } \\
\text { Spectral mixture } \\
\text { estimation }\end{array}$ & $\begin{array}{l}\text { Limited VUV } \\
\text { library }\end{array}$ \\
\hline & $\begin{array}{l}\text { Weber et al. } \\
\text { [52], } 2016\end{array}$ & $\begin{array}{l}\text { IL columns } \\
(30 \mathrm{~m} \times \\
250 \mu \mathrm{m} \times \\
0.2 \mu \mathrm{m})\end{array}$ & $\begin{array}{l}\text { VGA- } \\
100\end{array}$ & $\begin{array}{l}\text { Hydrocarbons in } \\
\text { diesel type } \\
\text { samples }\end{array}$ & & $\begin{array}{l}\text { Spectral filtering; } \\
\text { Group type } \\
\text { quantification; } \\
\text { Good agreement with } \\
\text { SFC results }\end{array}$ & $\begin{array}{l}\text { Larger } \\
\text { quantification } \\
\text { error for lower } \\
\text { abundance } \\
\text { species } \\
\text { (polyaromatics) }\end{array}$ \\
\hline & $\begin{array}{l}\text { Schenk et al. } \\
\text { [17], } 2016\end{array}$ & $\begin{array}{c}\text { RTX }-1 \\
(30 \mathrm{~m} \times \\
0.25 \mathrm{~mm} \times \\
0.25 \mu \mathrm{m})\end{array}$ & $\begin{array}{l}\text { VGA- } \\
100 \\
10 \mathrm{~Hz} \\
0.25 \\
\text { psi }\end{array}$ & $\begin{array}{c}\text { Alkyl } \\
\text { naphthalenes in } \\
\text { jet and diesel } \\
\text { fuel }\end{array}$ & & $\begin{array}{l}\text { Mixture estimation of } \\
\text { coeluting isomers (up } \\
\text { to relative abundance } \\
\text { difference of two } \\
\text { orders of magnitude); } \\
\text { Theoretical } \\
\text { computation of VUV } \\
\text { spectra }\end{array}$ & $\begin{array}{l}\text { More research } \\
\text { needed into } \\
\text { spectra } \\
\text { computation }\end{array}$ \\
\hline & $\begin{array}{l}\text { Walsh et al. } \\
\text { [25], } 2016\end{array}$ & $\begin{array}{c}\text { RXI-1 MS } \\
(30 \mathrm{~m} \times \\
0.25 \mathrm{~mm} \times \\
0.25 \mu \mathrm{m})\end{array}$ & $\begin{array}{l}\text { VGA- } \\
100\end{array}$ & $\begin{array}{l}\text { Hydrocarbons in } \\
\text { gasoline }\end{array}$ & & $\begin{array}{l}\text { TID allows spectral } \\
\text { mixture estimation; } \\
\text { Automated PIONA } \\
\text { analysis }\end{array}$ & $\begin{array}{l}\text { TID restricted for } \\
\text { more complex } \\
\text { samples owing to } \\
\text { limited VUV } \\
\text { library; } \\
\text { TID limited for } \\
\text { larger number of } \\
\text { coelutions }\end{array}$ \\
\hline & $\begin{array}{l}\text { Bai et al. [24], } \\
2017\end{array}$ & $\begin{array}{l}\text { Rt-Q-BOND } \\
(30 \mathrm{~m} \times \\
0.32 \mathrm{~mm} \times \\
10 \mu \mathrm{m})\end{array}$ & $\begin{array}{l}\text { VGA- } \\
100 \\
2.7 \mathrm{~Hz} \\
0.25 \\
\text { psi }\end{array}$ & $\begin{array}{l}\text { Benzene and } \\
\text { natural gas }\end{array}$ & & $\begin{array}{l}\text { Possibility of } \\
\text { calibrationless } \\
\text { quantification }\end{array}$ & $\begin{array}{l}\text { Errors associated } \\
\text { with cross sections } \\
\text { estimations }\end{array}$ \\
\hline & $\begin{array}{l}\text { Bai et al. [63], } \\
2018\end{array}$ & $\begin{array}{c}\text { RXI-1 MS } \\
(30 \mathrm{~m} \times \\
0.25 \mathrm{~mm} \times \\
0.25 \mu \mathrm{m})\end{array}$ & $\begin{array}{c}\text { VGA- } \\
100 \\
2.67 \\
\mathrm{~Hz} \\
0.25 \\
\text { psi }\end{array}$ & $\begin{array}{l}\text { Biomarkers in } \\
\text { diesel fuels } \\
\text { (pristane and } \\
\text { phytane) }\end{array}$ & & $\begin{array}{l}\text { Spectral filter } \\
\text { application offers } \\
\text { good selectivity for } \\
\text { saturates, mono and } \\
\text { aromatics; } \\
\text { Good spectral mixture } \\
\text { estimation abilities }\end{array}$ & $\begin{array}{l}\text { VUV library } \\
\text { limited to allow } \\
\text { proper } \\
\text { qualification and } \\
\text { quantification for } \\
\text { complex samples }\end{array}$ \\
\hline & $\begin{array}{l}\text { Liu et al. [58], } \\
2019\end{array}$ & $\begin{array}{l}\text { Monolithic } \\
\text { silica } \\
\text { column } \\
(10 \mathrm{~cm} \times \\
50 \mu \mathrm{m})\end{array}$ & $\begin{array}{l}\text { VGA- } \\
100 \\
4.5 \mathrm{~Hz} \\
0.5 \mathrm{psi}\end{array}$ & $\begin{array}{l}\text { Hydrogen, } \\
\text { carbon } \\
\text { monoxide, } \\
\text { carbon dioxide, } \\
\text { methane and } \\
\text { ethane in }\end{array}$ & & $\begin{array}{l}15 \text { s analysis; } \\
\text { Possibility of on-line } \\
\text { analysis; } \\
\text { Mixture estimation } \\
\text { capabilities }\end{array}$ & $\begin{array}{l}\text { Optimization of } \\
\text { make-up gas } \\
\text { influence on signal } \\
\text { intensity and } \\
\text { separation } \\
\text { efficiency; noise }\end{array}$ \\
\hline
\end{tabular}

This article is protected by copyright. All rights reserved. 


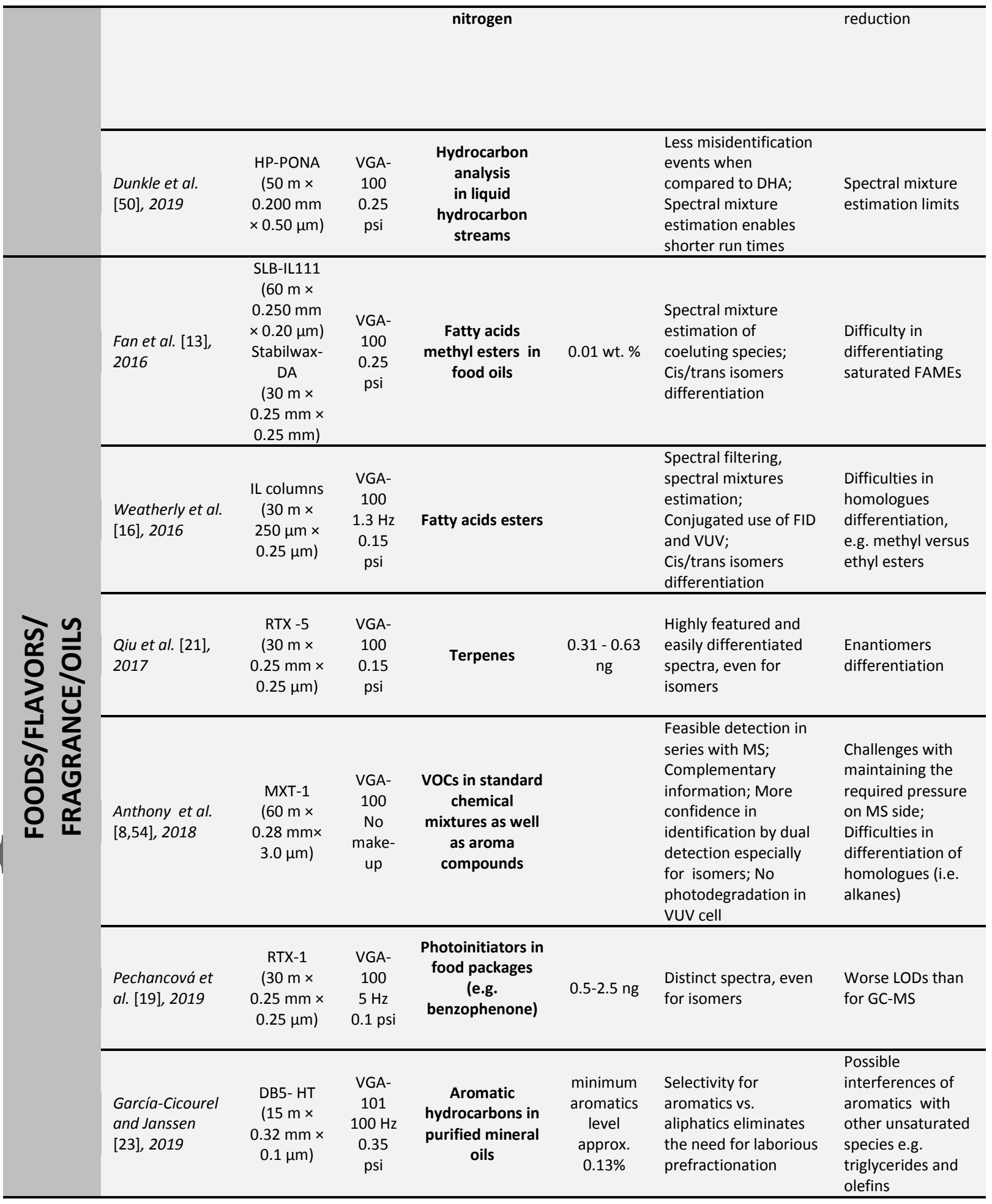




\begin{tabular}{|c|c|c|c|c|c|c|c|}
\hline \multirow{6}{*}{$\begin{array}{l}u \\
u \\
\sum_{u}^{u} \\
u \\
u \\
u \\
u\end{array}$} & $\begin{array}{l}\text { Schenk et al. } \\
\text { [18], } 2017\end{array}$ & $\begin{array}{c}\text { RTX-5 } \\
(30 \mathrm{~m} \times \\
0.25 \mathrm{~mm} \times \\
0.25 \mu \mathrm{m})\end{array}$ & $\begin{array}{l}\text { VGA- } \\
100 \\
10 \mathrm{~Hz} \\
0.25 \\
\text { psi }\end{array}$ & $\begin{array}{l}\text { Mono-, di, and tri- } \\
\text { saccharides }\end{array}$ & & $\begin{array}{l}\text { Effective separation, } \\
\text { spectral decomposition } \\
\text { and determination of } \\
\text { isobaric and isomeric } \\
\text { carbohydrate analytes }\end{array}$ & $\begin{array}{l}\text { Difficulties with } \\
\text { spectral mixture } \\
\text { estimation over a } \\
\text { wide range of relative } \\
\text { abundance for } \\
\text { compounds with } \\
\text { similar spectra } \\
\end{array}$ \\
\hline & $\begin{array}{l}\text { Muthal [65], } \\
2017\end{array}$ & $\begin{array}{l}\text { ZB-5 MS } \\
\text { Plus } \\
(15 \mathrm{~m} \times \\
0.25 \mathrm{~mm} \times \\
0.25 \mu \mathrm{m})\end{array}$ & $\begin{array}{c}\text { VGA- } \\
100 \\
4.5 \\
\mathrm{~Hz} \\
0.25 \\
\mathrm{psi} \\
\end{array}$ & Glucocorticoids & $20-60$ ng & $\begin{array}{l}\text { Identification of all } \\
\text { compounds despite } \\
\text { similar absorption } \\
\text { spectra }\end{array}$ & VUV library limited \\
\hline & $\begin{array}{l}\text { Santos et al. } \\
\text { [53], } 2018\end{array}$ & $\begin{array}{l}\text { FAMEWAX } \\
(30 \mathrm{~m} \times \\
0.25 \mathrm{~mm} \times \\
0.25 \mu \mathrm{m})\end{array}$ & $\begin{array}{l}\text { VGA- } \\
100 \\
10 \mathrm{~Hz} \\
0.25 \\
\text { psi }\end{array}$ & $\begin{array}{l}\text { Fatty acids in blood } \\
\text { plasma }\end{array}$ & $<0.42 \mu \mathrm{M}$ & $\begin{array}{l}\text { Mixture estimation } \\
\text { capabilities }\end{array}$ & $\begin{array}{l}\text { Difficulty of } \\
\text { distinguishing } \\
\text { positional isomers } \\
\text { owing to their similar } \\
\text { spectra }\end{array}$ \\
\hline & $\begin{array}{l}\text { Leghissa et } \\
\text { al. [57], } 2018\end{array}$ & $\begin{array}{c}\text { RTX-5 } \\
(30 \mathrm{~m} \times \\
0.25 \mathrm{~mm} \times \\
0.25 \mu \mathrm{m})\end{array}$ & $\begin{array}{l}\text { VGA- } \\
100 \\
5 \mathrm{~Hz} \\
0.25 \\
\text { psi }\end{array}$ & $\begin{array}{l}\text { Underivatized and } \\
\text { silylated } \\
\text { cannabinoids }\end{array}$ & 3-5 ppm & $\begin{array}{l}\text { Spectra distinctive; } \\
\text { Mixture estimation of } \\
\text { coeluted species }\end{array}$ & $\begin{array}{l}\text { Interference from the } \\
\text { background for more } \\
\text { complex samples }\end{array}$ \\
\hline & $\begin{array}{l}\text { Zheng et al. } \\
{[66], 2018}\end{array}$ & $\begin{array}{l}\text { DB-5 MS } \\
(30 \mathrm{~m} \times \\
0.32 \mathrm{~mm} \times \\
0.5 \mu \mathrm{m})\end{array}$ & $\begin{array}{l}\text { VGA- } \\
100 \\
10 \mathrm{~Hz} \\
0.25 \\
\text { psi }\end{array}$ & $\begin{array}{c}\text { Trace water } \\
\text { and water sensitive } \\
\text { 4-Ethoxy-1,1,1- } \\
\text { trifluoro-3-buten-2- } \\
\text { one }\end{array}$ & & $\begin{array}{l}\text { Peak tracking trough } \\
\text { spectra comparison } \\
\text { and retention times; } \\
\text { Selectivity trough } \\
\text { application of spectral } \\
\text { filters; } \\
\text { Reliable peak purity } \\
\text { assessment } \\
\end{array}$ & $\begin{array}{l}\text { High baseline noise } \\
\text { limits the attainable } \\
\text { dynamic range }\end{array}$ \\
\hline & $\begin{array}{l}\text { Buchalter et } \\
\text { al. [22], } 2019\end{array}$ & $\begin{array}{l}\text { Elite-5MS } \\
(30 \mathrm{~m} \times \\
0.25 \mathrm{~mm} \times \\
0.25 \mu \mathrm{m})\end{array}$ & $\begin{array}{l}\text { VGA- } \\
101 \\
4 \mathrm{~Hz} \\
0.35 \\
\text { psi }\end{array}$ & Fentanyl analogues & $\begin{array}{c}260-585 \\
\mathrm{ng} / \mathrm{l}\end{array}$ & $\begin{array}{l}\text { Tandem detection with } \\
\text { MS, } \\
\text { distinguishing between } \\
\text { positional isomers; } \\
\text { Mixture estimation ; } \\
\text { LODs lower than that of } \\
\text { cold EI MS detection }\end{array}$ & Sensitivity \\
\hline \multirow{3}{*}{ 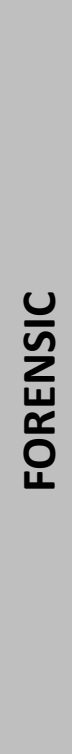 } & $\begin{array}{l}\text { Skultety et } \\
\text { al. [12], } 2017\end{array}$ & $\begin{array}{l}\text { Elite-5MS; } \\
\text { RTX-1 } \\
(30 \mathrm{~m} \times \\
0.25 \mathrm{~mm} \times \\
0.25 \mu \mathrm{m})\end{array}$ & $\begin{array}{c}\text { VGA- } \\
100 \\
1.3 \\
\text { and } \\
4.5 \\
\mathrm{~Hz} \\
0.15 \\
\text { and } \\
0.5 \\
\text { psi } \\
\end{array}$ & Designer drugs & $2-4 \mathrm{ng}$ & $\begin{array}{l}\text { Isomers distinctive } \\
\text { spectral features; } \\
\text { Spectral mixture } \\
\text { estimation }\end{array}$ & $\begin{array}{l}\text { Sensitivity limited; } \\
\text { Difficulties in } \\
\text { differentiation of } \\
\text { compounds with } \\
\text { similar spectral } \\
\text { features }\end{array}$ \\
\hline & $\begin{array}{l}\text { Cruse and } \\
\text { Goodpaster } \\
\text { [67], } 2019\end{array}$ & $\begin{array}{c}\text { ZB-5 MS } \\
\text { column } \\
(10 \mathrm{~m} \times \\
0.18 \mathrm{~mm} \times \\
0.18 \mu \mathrm{m})\end{array}$ & $\begin{array}{c}\text { VGA- } \\
101 \\
4.5 \\
\mathrm{~Hz} \\
0.35 \\
\text { psi }\end{array}$ & $\begin{array}{l}\text { Nitrate ester } \\
\text { explosives }\end{array}$ & $\begin{array}{l}\text { hundreds } \\
\text { of ppm }\end{array}$ & $\begin{array}{l}\text { Analytes successfully } \\
\text { discerned; } \\
\text { Spectral filtering and } \\
\text { mixture estimation aid } \\
\text { in proper identification }\end{array}$ & $\begin{array}{l}\text { LODs need to be } \\
\text { improved }\end{array}$ \\
\hline & $\begin{array}{l}\text { Reiss et al. } \\
\text { [20], } 2019\end{array}$ & $\begin{array}{l}\text { RXI-1 MS } \\
(30 \mathrm{~m} \times 0.32 \\
\mathrm{mm} \times 4 \mu \mathrm{m})\end{array}$ & $\begin{array}{l}\text { VGA- } \\
100 \\
4.5 \\
\mathrm{~Hz} \\
1.5 \\
\text { psi }\end{array}$ & $\begin{array}{l}\text { Drug and explosive } \\
\text { precursors as well as } \\
\text { chemical warfare } \\
\text { agent simulants }\end{array}$ & $0.7 \mathrm{ng}$ & $\begin{array}{l}\text { Isomers differentiation; } \\
\text { Spectral mixture } \\
\text { estimation }\end{array}$ & $\begin{array}{l}\text { Spectral mixture } \\
\text { estimation limitations }\end{array}$ \\
\hline
\end{tabular}




\begin{tabular}{|c|c|c|c|c|c|c|c|}
\hline & $\begin{array}{l}\text { Roberson } \\
\text { and } \\
\text { Goodpaster } \\
\text { [68], } 2019\end{array}$ & $\begin{array}{c}\text { HP-5 MS } \\
(30 \mathrm{~m} \times 250 \\
\mu \mathrm{m} \times 0.25 \\
\mu \mathrm{m})\end{array}$ & $\begin{array}{l}\text { VGA- } \\
101 \\
6 \mathrm{~Hz} \\
0.35 \\
\text { psi }\end{array}$ & Phenethylamines & $10 \mathrm{ng}$ & $\begin{array}{l}\text { Identification of all } \\
\text { species possible } \\
\text { despite similar spectral } \\
\text { features; } \\
\text { Stereoisomers possible } \\
\text { to differentiate trough } \\
\text { application of } \\
\text { chemometrics }\end{array}$ & $\begin{array}{l}\text { Spectral library } \\
\text { limited }\end{array}$ \\
\hline \multirow{4}{*}{ 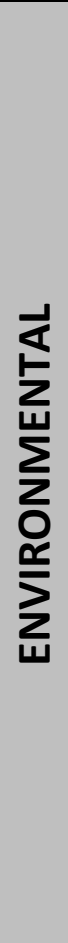 } & $\begin{array}{l}\text { Fan et al. } \\
\text { [15], } 2015\end{array}$ & $\begin{array}{c}\text { HP-5 MS } \\
(30 \mathrm{~m} \times 250 \\
\mu \mathrm{m} \times 0.25 \\
\mu \mathrm{m}) \\
\mathrm{ZB}-5 \\
(15 \mathrm{~m} \times 250 \\
\mu \mathrm{m} \times 0.25 \\
\mu \mathrm{m})\end{array}$ & $\begin{array}{l}\text { VGA- } \\
100 \\
0.1- \\
0.25 \\
\text { psi }\end{array}$ & Pesticides & $\begin{array}{l}500 \text { and } \\
125 \text { pg for } \\
\text { dieldrin } \\
\text { and } p, p^{\prime}- \\
\text { DDE }\end{array}$ & $\begin{array}{l}\text { Spectral filters for } \\
\text { differentiation of } \\
\text { aromatics and non- } \\
\text { aromatics; } \\
\text { Isomers non-amenable } \\
\text { to MS demonstrate } \\
\text { distinctive spectra. } \\
\text { Spectral mixture } \\
\text { estimation } \\
\end{array}$ & $\begin{array}{l}\text { Higher sensitivity for } \\
\text { aromatics }\end{array}$ \\
\hline & $\begin{array}{l}\text { Qiu et al. } \\
\text { [56], } 2017\end{array}$ & $\begin{array}{c}\text { RTX-PCB } \\
(30 \mathrm{~m} \times \\
0.25 \mathrm{~mm} \times \\
0.25 \mu \mathrm{m} \\
\text { and } \\
60 \mathrm{~m} \times 0.18 \\
\mathrm{~mm} \times 0.18 \\
\mu \mathrm{m}) \\
\end{array}$ & $\begin{array}{l}\text { VGA- } \\
100 \\
3.6 \\
\mathrm{~Hz} \\
0.15 \\
\text { psi }\end{array}$ & $\begin{array}{l}\text { Polychlorinated } \\
\text { biphenyls }\end{array}$ & $\begin{array}{c}0.1-0.15 \\
n g\end{array}$ & $\begin{array}{l}\text { All PCBs have distinct } \\
\text { spectra; } \\
\text { Coeluted ones } \\
\text { differentiated by } \\
\text { applying TID }\end{array}$ & $\begin{array}{l}\text { Limits of TID need to } \\
\text { be investigated }\end{array}$ \\
\hline & $\begin{array}{l}\text { Santos et al. } \\
\text { [69], } 2018 \\
\text { Santos et al. } \\
\text { [70], } 2019\end{array}$ & $\begin{array}{l}\text { Stabilwax } \\
(30 \mathrm{~m} \times \\
0.25 \mathrm{~mm} \times \\
0.25 \mu \mathrm{m})\end{array}$ & $\begin{array}{l}\text { VGA- } \\
100 \\
10 \mathrm{~Hz} \\
0.25 \\
\text { psi }\end{array}$ & $\begin{array}{l}\text { Fatty acids methyl } \\
\text { esters for bacterial } \\
\text { identification }\end{array}$ & & $\begin{array}{l}\text { PCA cluster analysis } \\
\text { allows good } \\
\text { differentiation of } \\
\text { bacterial species }\end{array}$ & $\begin{array}{l}\text { VUV library limited } \\
\text { for branched FAs }\end{array}$ \\
\hline & $\begin{array}{l}\text { Schenk at al. } \\
\text { [64], } 2019\end{array}$ & $\begin{array}{l}\text { RXI-624 Sil } \\
\text { MS } \\
(30 \mathrm{~m} \times \\
0.25 \mathrm{~mm} \times \\
1.4 \mu \mathrm{m})\end{array}$ & $\begin{array}{c}\text { VGA- } \\
100 \\
4.5 \\
\mathrm{~Hz} \\
0.25 \\
\text { psi }\end{array}$ & $\begin{array}{l}\text { Formaldehyde and } \\
\text { other leachates from } \\
\text { proppants }\end{array}$ & 20 mg/l & $\begin{array}{l}\text { Formaldehyde unique } \\
\text { absorbance spectrum, } \\
\text { enhanced selectivity }\end{array}$ & $\begin{array}{l}\text { Sensitivity, } \\
\text { derivatization }\end{array}$ \\
\hline \multirow{4}{*}{$\frac{\propto}{\Perp}$} & $\begin{array}{l}\text { Shear-Laude } \\
\text { [71], } 2017\end{array}$ & $\begin{array}{l}\text { Watercol } \\
1900 \\
(30 \mathrm{~m} \times \\
0.25 \mathrm{~mm} \times \\
0.20 \mu \mathrm{m})\end{array}$ & $\begin{array}{c}\text { VGA- } \\
100 \\
4.5 \\
\mathrm{~Hz} \\
0.25 \\
\text { psi }\end{array}$ & Water in solvents & $2.5 \mathrm{ppm}$ & $\begin{array}{l}\text { Good repeatability; } \\
\text { Quick and efficient and } \\
\text { does not require the } \\
\text { use of chemical } \\
\text { reagents for water } \\
\text { analysis }\end{array}$ & $\begin{array}{l}\text { Limited dynamic } \\
\text { range }\end{array}$ \\
\hline & $\begin{array}{l}\text { Weston et al. } \\
\text { [61], } 2018\end{array}$ & $\begin{array}{c}\text { RTX-1 } \\
(30 \mathrm{~m} \times \\
0.25 \mathrm{~mm} \times \\
0.25 \mu \mathrm{m})\end{array}$ & $\begin{array}{l}\text { VGA- } \\
100 \\
3 \mathrm{~Hz} \\
0.15 \\
\text { psi }\end{array}$ & $\begin{array}{l}\text { Stable-isotopically- } \\
\text { labeled internal } \\
\text { standards of } \\
\text { benzene }\end{array}$ & & $\begin{array}{l}\text { Spectral mixture } \\
\text { estimation capabilities }\end{array}$ & $\begin{array}{l}\text { Sufficient spectra } \\
\text { dissimilarity (e.g. SSR } \\
>1 \text { or higher) is } \\
\text { needed for mixture } \\
\text { estimation; } \\
\text { Possibility of } \\
\text { interferences } \\
\end{array}$ \\
\hline & $\begin{array}{l}\text { Ponduru et } \\
\text { al. [27], } 2018\end{array}$ & $\begin{array}{c}\text { RXI-5 } \\
(30 \mathrm{~m} \times \\
0.25 \mathrm{~mm} \times \\
0.25 \mu \mathrm{m})\end{array}$ & $\begin{array}{l}\text { VGA- } \\
100 \\
0.15 \\
\text { psi }\end{array}$ & $\begin{array}{l}\text { Polycyclic aromatic } \\
\text { hydrocarbons and } \\
\text { their oxidation } \\
\text { products }\end{array}$ & & $\begin{array}{l}\text { Good identification } \\
\text { capabilities owing to } \\
\text { rich spectral features; } \\
\text { Computation of } \\
\text { theoretical spectra }\end{array}$ & $\begin{array}{l}\text { Computational } \\
\text { methods } \\
\text { improvements } \\
\text { needed; } \\
\text { Limited sensitivity } \\
\end{array}$ \\
\hline & $\begin{array}{l}\text { Mao et al. } \\
\text { [28], } 2019\end{array}$ & / & $\begin{array}{l}\text { VGA- } \\
100\end{array}$ & PIONA molecules & & $\begin{array}{l}\text { Computation of PIONA } \\
\text { molecules theoretical } \\
\text { spectra; Optimized } \\
\text { computation } \\
\text { parameters stable over } \\
\text { wide range of PIONA } \\
\text { compounds }\end{array}$ & $\begin{array}{l}\text { Consideration of } \\
\text { single fixed molecule } \\
\text { geometry limits the } \\
\text { result of computation }\end{array}$ \\
\hline
\end{tabular}


Table 2 Overview of the early GC $\times$ GC-VUV applications.

\begin{tabular}{|c|c|c|c|c|c|c|}
\hline Reference & $\mathbf{G C} \times \mathbf{G C}$ & VUV & $\begin{array}{c}\text { Sample } \\
\text { type }\end{array}$ & LODs & $\begin{array}{c}\text { VUV } \\
\text { advantages }\end{array}$ & $\begin{array}{c}\text { VUV } \\
\text { limitations }\end{array}$ \\
\hline $\begin{array}{c}\text { Groger et al. [40], } \\
2016\end{array}$ & $\begin{array}{c}\text { Cryo GCxGC } \\
\text { 007-FFAP } \\
(30 \mathrm{~m} \times 0.25 \mathrm{~mm} \times 1 \mu \mathrm{m}) \\
007-1701 \\
(3 \mathrm{~m} \times 0.1 \mathrm{~mm} \times 0.5 \mu \mathrm{m}) \\
1.2 \mathrm{~mL} \mathrm{~min}^{-1}\end{array}$ & $\begin{array}{l}\text { VGA- } \\
100 \\
1.5 \mathrm{psi} \\
50 \mathrm{~Hz}\end{array}$ & $\begin{array}{l}\text { Hydrocarbons } \\
\text { in diesel fuel } \\
\text { and Fischer- } \\
\text { Tropsch } \\
\text { syncrude }\end{array}$ & low ng & $\begin{array}{l}\text { Distinctive spectral } \\
\text { features for most } \\
\text { compounds, } \\
\text { discrimination } \\
\text { between isomeric } \\
\text { and isobaric species, } \\
\text { oxygenates; Spectral } \\
\text { filtering }\end{array}$ & $\begin{array}{l}\text { Limited selectivity } \\
\text { for homologues }\end{array}$ \\
\hline $\begin{array}{c}\text { Gruber et al. [48], } \\
2016\end{array}$ & $\begin{array}{c}\text { Cryo GCxGC } \\
\text { PEG } \\
(30 \mathrm{~m} \times 0.25 \mathrm{~mm} \times 1 \mu \mathrm{m}) \\
14 \% \text { cyanopropylphenyl } \\
\text { methylpolysiloxane } \\
(3 \mathrm{~m} \times 0.1 \mathrm{~mm} \times 0.5 \mu \mathrm{m}) \\
1.3 \mathrm{~mL} \mathrm{~min}^{-1}\end{array}$ & $\begin{array}{l}\text { VGA- } \\
100 \\
1.5 \mathrm{psi} \\
90 \mathrm{~Hz}\end{array}$ & $\begin{array}{c}\text { Polar VOCs in } \\
\text { breath } \\
\text { gas }\end{array}$ & low ng & $\begin{array}{l}\text { Additional selectivity } \\
\text { gained through the } \\
\text { application of } \\
\text { spectral filters for } \\
\text { saturates and } \\
\text { unsaturates }\end{array}$ & $\begin{array}{l}\text { Limited selectivity } \\
\text { for homologues }\end{array}$ \\
\hline $\begin{array}{l}\text { Zoccali et al. [55], } \\
2017\end{array}$ & $\begin{array}{c}\text { Flow GCxGC } \\
\text { SLB-5 MS } \\
(30 \mathrm{~m} \times 0.25 \mathrm{~mm} \times 0.25 \\
\mu \mathrm{m}) 0.45 \mathrm{~mL} \mathrm{~min}-1 \\
\text { Supelcowax } \\
\left(10.5 \mathrm{~m} \times 0.32 \mathrm{~mm}^{-1}\right. \\
0.25 \mu \mathrm{m}) 12 \mathrm{~mL} \mathrm{~min}^{-1} \\
\end{array}$ & $\begin{array}{l}\text { VGA- } \\
100 \\
33 \mathrm{~Hz}\end{array}$ & $\begin{array}{c}\text { Bio-diesel fuel } \\
\text { and fatty acid } \\
\text { samples }\end{array}$ & $<6 \mathrm{ppm}$ & $\begin{array}{l}\text { Easy coupling with } \\
\text { flow-GCxGC; } \\
\text { Spectral mixtures } \\
\text { estimation and } \\
\text { pseudo-absolute } \\
\text { quantification }\end{array}$ & $\begin{array}{l}\text { Error propagation } \\
\text { from determined } \\
\text { cross-sections }\end{array}$ \\
\hline $\begin{array}{c}\text { Jennerwein et al. } \\
\text { [97], } 2019\end{array}$ & $\begin{array}{c}\text { Flow GCxGC } \\
\text { ZB-35HT } \\
(20 \mathrm{~m} \times 0.18 \mathrm{~mm} \times 0.18 \\
\mu \mathrm{m}) \\
\text { ZB-1MS } \\
(5 \mathrm{~m} \times 0.25 \mathrm{~mm} \times 0.1 \\
\mu \mathrm{m})\end{array}$ & $\begin{array}{l}\text { VGA- } \\
100\end{array}$ & $\begin{array}{l}\text { Hydrocarbons } \\
\text { in gasoline, } \\
\text { middle } \\
\text { distillates and } \\
\text { crude oil }\end{array}$ & & $\begin{array}{l}\text { Amenable to } \\
\text { hyphenation with } \\
\text { FID; } \\
\text { Assignment of } \\
\text { compound classes } \\
\text { without full } \\
\text { chromatographic } \\
\text { separation }\end{array}$ & $\begin{array}{l}\text { More reliable and } \\
\text { more sensitive } \\
\text { quantification by } \\
\text { FID }\end{array}$ \\
\hline
\end{tabular}

